\title{
Leishmania-Host Interplay: The Everlasting Rivalry
}

\author{
A. Martiny and M.A. Vannier-Santos*
}

Centro de Pesquisas Gonçalo Moniz-FIOCRUZ, Rua Waldemar Falcão 121, Brotas, Salvador, Bahia, Brasil

\begin{abstract}
Parasitic protozoa of the genus Leishmania infect mammalian mononuclear phagocytic cells causing a potentially fatal disease with a broad spectrum of clinical manifestations. The drugs of choice used in the leishmaniasis therapy are significantly toxic, expensive and faced with a growing frequency of refractory infections. Thus the search for new leishmanicidal compounds is urgently required. In order to perform a proper drug design and to understand the modes of action of such compounds it is necessary to elucidade the intrincate cellular and molecular events that orchestrate the parasite biology. To invade host cells Leishmania recruit different surface receptors that may assist engaging the microbicidal responses. Even before gaining the intracellular millieu these pathogens can deactivate and/or subvert the phagocyte signal transduction machinery rendering these cells permissive to infection. In the present review we attempted to approach some of the most relevant cellular and biochemical invasion strategies employed by Leishmania parasites.
\end{abstract}

Key words: Leishmania, parasites, signal transduction, receptor, chemotherapy, evasion mechanisms.

\section{INTRODUCTION}

Leishmania parasites were independently described by William Leishman and Charles Donovan in 1903, but were previously observed by David D. Cuningham in 1885 and Peter Borovsky in 1898. These parasites were mistaken for other protozoa and the genus Leishmania was proposed by James Wright only in 1903.

Several syndromes are subsumed under the term leishmaniasis ranging from the self-healing cutaneous lesions to the potentially fatal visceral form. It is estimated that 12 million people are infected by over twenty Leishmania species with about two million cases reported annually and 350 million people living in endemic areas under the risk of infection [91]. Leishmaniasis is found in at least 88 countries but more than $90 \%$ of cases are observed in underdeveloped or developing countries such as Brazil, Bangladesh, India and Sudan. The relevance of this parasitic disease is further stressed out by the rise of Leishmania-HIV co-infection in many parts of the world including European countries such as Spain, Italy, France and Portugal where up to $9 \%$ of the AIDS patients suffer from visceral leishmaniasis [92].

Leishmania spp. are digenetic trypanosomatid parasites which infect humans and other mammals. In the invertebrate phlebotomine sand fly host parasites proliferate in the promastigote (flagelate) form in the insect gut [128] whereas in the vertebrate host the protozoa are obligate intracellular parasites in the amastigote (non-motile) form infecting mostly mononuclear phagocytes [62,313].

\section{ULTRASTRUCTURE AND BIOLOGY}

Promastigotes are elongated cells with a cell body measuring 5-20 x 1-4 $\mu \mathrm{m}$ and an anterior flagellum up to $20 \mu \mathrm{m}$

*Address correspondence to this author at the Centro de Pesquisas Gonçalo Moniz-FIOCRUZ, Rua Waldemar Falcão 121, Brotas, Salvador, Bahia 40295-001, Brasil; Tel: + 55-71-356-4320 ext. 236; Fax + 55-71-344-0341;

E-mail: vannier@cpqgm.fiocruz.br long. Amastigotes are oblong cells measuring about $2 \times 4$ $\mu \mathrm{m}$. In both developmental forms the flagellum emerges from a flagellar pocket and in the amastigote form it is almost completely restricted to it, so it is only observed by electron microscopy. The characteristic axonemal structure of the flagellum can be observed only in promastigote forms, consisting of nine pairs of peripheral axonemal microtubules encircling a central pair that arises from the first basal plate and can be found distal to the basal body. It can be observed that in the amastigote an unusual arrangement of the axoneme and the $9+2$ configuration is disrupted near the flagellar tip [4].

The parasite cells are shaped by a layer of parallel subpellicular microtubules spaced about $44 \mathrm{~nm}$ apart, running longitudinally underneath the plasma membrane at a distance of $\sim 8.5 \mathrm{~nm}$ all over the cell body [reviewed in 93]. These cytoskeletal structures somehow can determine the distribution of membrane proteins and sterol molecules [234] on the parasite surface. The number of subpellicular microtubules varies according to the developmental form of the parasite. They terminate near the flagellar pocket that presents only four associated microtubules [54] thought to take part in vesicle transport. Endocytosis and exocytosis take place in the flagellar pocket (FP) reservoir of both parasite forms [325]. The amastigote FP presents numerous integral membrane proteins particularly found at the posterior portion [234]. This flagellar pocket domain may take part in the vesicle docking during exocytosis [316]. The uptake of several macromolecules was described in promastigotes and amastigotes both in axenic and inside macrophages $[45,68$, $261,278]$. Interestingly both promastigotes and amastigotes are able to exchange membrane components with host cells in a dynamic and developmentally regulated process [136]. Leishmania within the parasitophorous vacuole (PV) acquire macrophage cytoplasmic molecules via membrane transporters or fusion of autophagic vacuoles [272]. The amastigote forms of New World Leishmania belonging to the L. mexicana complex display unique lysosome-like membrane- 
bounded organelles termed megasomes presenting spongylike matrix which may occupy as much as $15 \%$ of the cell volume [68]. Megasomes are cysteine proteinase-rich organelles [100] associated to accumulation and possible degradation of endocytosed macromolecules. We have previously observed that transferrin is ingested by both intracellular and axenic amastigotes and subsequently delivered to megasomes [45]. The endocytic apparatus of promatigotes is significantly less studied but recently an unusual post-Golgi tubular lysosome-like compartment termed multivesicular tubule (MVT) streching along the length of the cell body has been described [147, 208]. The MVT is associated to one or two of the cytoplasmic microtubules of the flagellar pocket as well as with the Golgi apparatus at the anterior pole and become intercalated with the subpellicular microtubules at the posterior end, which may explain the contraction of the organelle during the cell cycle. It is speculated that it may originate or derive from the amastigote megasome due to its cysteine proteinase activity. The cysteine proteinase activity of Leishmania, likewise several other parasites, plays a relevant role in the infection outcome. It was shown that leupeptin and antipain treatment and target-deletion of cysteine proteinase result in decreased amastigote intracellular survival in macrophages [5]. In addition cysteine proteinase may take part in the MHC class II degradation by intracellular amastigotes [9, 289]. These findings suggest that cysteine proteinases may comprise useful chemotherapy targets [112].

The presence of half-empty vacuoles in trypanosomatid parasites as well as other microorganisms was described early in this century. These vacuoles were called 'volutin' or 'metachromatic' granules, 'inclusion' or 'electron-dense' vacuoles and were also mistaken for lysosomes. Docampo and coworkers found that this acidic organelle, called acidocalcisome, is a $\mathrm{Ca}^{2+}$ storage compartment, rich in pyrophosphate polyphosphate, $\mathrm{Mg}^{2+}, \mathrm{Na}^{+}$and in some cases $\mathrm{Zn}^{2+}$ [reviewed in 97]. The presence of $\mathrm{Ca}^{2+}-\mathrm{H}^{+}$ATPase, $\mathrm{Ca}^{2+}-\mathrm{H}^{+}$ exchanger, $\mathrm{Na}^{+}-\mathrm{H}^{+}$antiporter and vacuolar-type $\mathrm{H}^{+}$translocating pyrophosphatase activities in the membrane of acidocalcisomes was confirmed in promastigotes of $L$. $(L$.) donovani. Besides storage and release of large amounts of $\mathrm{Ca}^{2+}$ for signaling, acidocalcisomes are thought to be involved in $\mathrm{pH}$ homeostasis and osmoregulation in parasites. Various findings suggest that this organelle may comprise a chemotherapeutic target due to its relation to plant vacuoles. The vacuolar-type $\mathrm{H}^{+}$-translocating pyrophosphatase for instance has only been previously described in plants and bacteria. Its activity in most trypanosomatids, the apicomplexa Toxoplasma gondii and Plasmodium falciparum and $P$. berghei [97] reinforces this assumption. In this regard, we have found azole and allylamine compounds induce profound alterations and autophagic degradation associated with the formation of numerous acidocalcisome-like organelles in L. (L.) amazonensis promastigotes and intracellular amastigotes $[315,320]$. Lectin-labeled acidocalcisome-like compartments were reported [318] but these data should be interpreted with caution since structurally similar organelles may be mistaken.

Another unique organelle present in Leishmania and other trypanosomatids is the glycosome, a highly specialized organelle involved in glycolytic ATP generation. Gly- cosomes are globular organelles related to the mammalian peroxisomes [94], with a mean diameter of $0.2-0.3 \mu \mathrm{m}$ surrounded by a single membrane unit and despite its possible endosymbiont origin it so far contains no detectable DNA or RNA. Cells may present between 10 and 100 glycosomes which also take part in other processes including $\beta$-oxidation of fatty acids, pyrimidine biosynthesis and purine salvage [224]. It also contains at least two Fe-SOD isoforms that help protecting glycosomes from $\mathrm{O}_{2}^{-}$toxicity [238]. Compartimentalization of glycolytic enzymes was shown to increase the efficiency of glycolysis by at least an order of magnitude. Nevertheless, recent studies in T. brucei suggest that the glycosomal membrane did not significantly affect the steady-state glycolytic flux but rather it may participate in enzyme regulation by limiting the concentration of the substrates and products of some enzymes within a narrow range. Otherwise, the accumulation at high rates of such metabolites would result in osmotic dysfunction and cell death [193]. This assumption was not confirmed in Leishmania parasites. The biogenesis of the glycosomes has been conserved throughout evolution. In trypanosomatids the glycolysis enzymes exist as both cytoplasmic and glycosomal isozymes encoded by distinct genes. Proteins are synthesized in the cytoplasm on free polysomes and imported posttranslationally into the organelles within 3 to 5 minutes after synthesis, with no proteolytical cleavage of the signal sequence or other modifications detected after import. Glycosomal targeting was shown to require a $\mathrm{C}$-terminus SKL (Ser-Lys-Leu)-like tripeptide. Nevertheless, the sole presence of the SKL sequence does not necessarily imply glycosomal localization. Other domains may be required since this tripeptide is also found in the mitochondrial trypanothione reductase and in the cytoplasmic glucosephosphate isomerase from $L$. (L.) mexicana. It is not known whether the sequence upstream of the C-teminal tripeptide may play a role in import suitability. The disruption of the glycolytic pathway in trypanosomatids by compounds that target the signal sequence of the glycosome enzymes may provide potential leishmanicidal therapies. Despite this efficient glycolytic pathway, promastigotes preferentially utilize aminoacids such as proline as carbon sources. The uptake of glucose is more relevant in the late log phase of growth. The use of proline instead of glucose for energetic purpose may be an important adaptation for survival in the protein-rich insect bloodmeal [218]. Both proline and glucose are incorporated via proton-driven synport [124]. Genes coding for two members of glucose transporter superfamily were isolated from Leishmania species [167]. These transporters differ in their N-terminal hydrophilic domains responsible for sorting to the FP, flagellar and plasma membranes.

Leishmania, like the other trypanosomatid parasites, present a single branched mitochondrion that may extend the whole length of the cell with a large DNA content (nearly $15 \%$ of the total cell DNA) in a region termed kinetoplast, located in the vicinity of the flagellum basal body. Over $90 \%$ of the k-DNA in a parasite not undergoing replication is comprised of 5000-10000 catenated copies of the minicircles with $800-1200 \mathrm{bp}$ each. The remaining DNA forms $25-50$ copies of the maxicircles with about $20 \mathrm{~kb}$ each. It is not clear why trypanosomatid parasites organize their mitochondrial DNA in such a network. Isolated k-DNA observed by elec- 
tron microscopy is a planar structure, elliptically shaped in which neighbouring minicircles are joint by single interlocks. In non-replicating parasites, the minicircles are covalently closed but still topologically relaxed [245], contrary to other circular DNAs that are negatively supercoiled. In vivo the network is probably compacted into a disk with the thickness about half the circunference of a minicircle. Highly basic DNA-binding proteins localized in the disk and a segment of bent helix present in each minicircle is probably involved in stabilization of the condensed conformation of the network. In replicating cells, division of the kinetoplast preceedes nuclear division and the outgrowth of a new flagellum, the network disk being flanked by two complexes of proteins involved in DNA replication, such as topoisomerase II and DNA polimerase. The topoisomerase II releases a few hundred minicircles from the catenated network at a time permiting replication in a mechanism similar as that of plasmids and other circular DNAs.

The maxicircles resemble eukaryotic mitochondrial DNA in that they encode rRNA [42] and some proteins mostly involved in mitochondrial energy transduction such as subunits of cytochrome oxidase and NADH dehydrogenase [280]. The expression of these protein coding genes in maxicircles is however very intrincated, the transcripts undergoing intense RNA editing, a process in which uridine residues are added or deleted to create open reading frames (ORFs). RNA editing can be extensive and in some cases more than half the nucleotides in an ORF are added by this process [30]. The minicircles were misunderstood for a long period and it is now known that they encode small template sequences that guide the editing of the kRNA [42,107]. There are also minicircles that are replication intermediates.

Nuclei of both Leishmania stages are enveloped by the ER punctuated by pores similar to other eukaryotic cells. A proeminent centrally positioned nucleolus $0.6-1.0 \mu \mathrm{m}$ in diameter can be observed and nuclear chromatin is arranged peripherally. The Leishmania genome size is aproximately $34 \mathrm{Mb}$ and the chromosomes range from 0.3 to $2.8 \mathrm{Mb}$. The karyotype is conserved among Leishmania species but considerable size polymorphism is observed and the genes are organized in 34 to 36 chromosomes. The leishmanial genome presents polycystronic sequences with a single promoter for DNA polymerase recognition [299]. Interestingly both the nuclear and the kinetoplast chromatin present lectinbinding sites indicating the presence of carbohydrates within these Leishmania compartments [318].

\section{PARASITE DEVELOPMENT IN THE INVER- TEBRATE HOST}

Leishmania spp. proliferate extracellularly within the gut of phlebotomine sand fly hosts in the promastigote form. Sexual reproduction was not inequivocally demonstrated although light microscopy images suggesting genetic exchange [288] and interespecific hybrids were found [21]. The sand fly hosts are mostly of the Phlebotomus and the Lutzomyia genera in the Old and New Worlds, respectively. Promastigote attachment to the insect gut wall is generally confined to the midgut, except the species of the L. braziliensis complex (subgenus Viannia) e.g. L. (Viannia) braziliensis, which also bind to the hindgut at the pilorous region.
The amastigotes uptaken during the phlebotomine bloodmeal transform into promastigotes within the insect gut. Promastigotes taken from sand fly gut three days after bloodmeal are avirulent whereas the ones taken 7-8 days after feeding are highly virulent to mice [264, 265]. During this period parasites undergo profound morphological and biochemical modifications as they transform from noninfective procyclics to the infective metacyclic forms. The proliferative promastigotes, i.e. procyclics, may be found in different morphotypes. Gossage and collegues [128] have suggested that procyclics are the forms present in the bloodmeal in the abdominal midgut, which subsequently give rise to non-dividing nectomonads. The nectomonads are large promastigotes within the sac-like chitinous peritrophic matrix. With the disruption of the anterior part of this matrix by promastigote chitinolytic enzymes [274] the parasites migrate and attach to the microvilli of the midgut epithelial cells. They give rise to proliferating leptomonads in the anterior midgut and subsequently transform into non-dividing metacyclics. Some authors also describe the presence of short and broad haptomonad forms. Some of these may reach the oesophagus and pharynx where they transform into paramastigotes [reviewed in 273] the shortest promastigotes in which the kinetoplast may be seen beside the nucleus. It was suggested that after differentiation to metacyclics, the remaining non-infective parasites undergo programmed cell death [83] allowing the survival of at least some organanisms of the parasite population by preserving the limited supply of essencial nutrients in the midgut.

The metacyclics are usually shorter and thinner than procyclics with increased motility and a relatively longer flagellum. Besides the morphological alterations, extensive biochemical modifications can be observed, including the expression and activity of cell surface molecules. The major surface glycoconjugate of the promastigote form, lipophosphoglycan (LPG), is a large glycolipid comprised of repeating phosphorylated saccharide units (di-, tri- or tetrasaccharides) polymer linked by monophosphate bridges, connected to a carbohydrate core, that in $L$. (L.) donovani is a phosphohexasaccharide, anchored by lyso-alkylphosphatidylinositol. Leishmania (L.) donovani promastigotes present about $1.25 \times 10^{6}$ copies of LPG per cell [reviewed in 35,310$]$. During metacyclogenesis LPG undergoes structural alterations [263] being elongated due to the addition of phosphorylated saccharides in a way that it can almost double its length in some Leishmania species. Also, terminal carbohydrate moieties on repeating saccharidephosphate may be replaced. LPG modification downmodulates its recognition by the $65 \mathrm{kDa}$ LPG-binding protein in the midgut microvilli [96] allowing the infective metacyclics to move forward to the foregut $[266,267]$. The ability of a Leishmania species to infect a particular phlebotomine depends on its carbohydrate composition [236]. The phosphoglycan of LPG and LPG-related molecules can promote the survival of $L$. (L.) major but not $L$. (L.) donovani in the vector gut and was earlier suggested to protect the parasite from proteolytic activity in the gut of $P h$. papatasi [reviewed in 273]. However, recent studies using LPG-deficient $L$. (L.) major mutants demonstrated that these parasites present only a slight reduction of survival in the early stages of develpment in the sand fly suggesting a minor role in the protection 
against digestive hydrolysis in the bloodfed gut [267]. The ability of LPG and PPG to scavenge oxygen free radicals may be relevant for the promastigote survival in the hemoglobin-rich environment of the bloodmeal and large amounts of excreted phosphoglycans can be observed within the epithelial cells lining the sand fly gut [82]. These phosphoglycan-rich molecules are thus essential for successful colonization of Ph. papatasi by $L$. (L.) major [267].

Metacyclics also express increased levels of gp63, the most abundant surface protein of promastigotes that constitutes up to $2 \%$ of all cellular proteins. Glycoprotein 63 , also known as promastigote surface protease (PSP) or leishmanolysin, is a $\mathrm{Zn}^{2+}$-stimulated GPI-anchored metalloproteinase [44]. In the sand fly gut it may help degrading extracellular hemoglobin [64]. Metacyclics also express enhanced membrane-bound and secreted acid phosphatase (SAP) and cysteine proteinase activities. Both molecules may be involved in the infection process. Acid phosphatase (AcP) was correlated to parasite virulence in $L$. (L.) donovani species [158, 283] but its role is still not undoubtfully defined as target deletion $L$. (L.) mexicana SAP mutants do not present decreased in vitro or in vivo infectivity for vertebrate cells [327].

Efficient transmission of metacyclics depends not only on parasite competence to colonize the phlebotomine foregut but also on the disease-like states induced by the parasite in the sand fly. These modifications include the inability of infected sand flies to ingest blood and degeneration of the cardiac valve [274]. A carbohydrate-rich gel-like threedimentional network is thought to cause the occlusion of the gut lumen at the foregut-midgut transition, oesophagus and pharynx, which contains high numbers of parasites. This network is mainly composed of a high molecular weight mucin-like filamentous proteophosphoglycan (fPPG) secreted by promastigote forms [294]. This fPPG molecule often exceeds $6 \mu \mathrm{m}$ in length. Concurrently, a chitinolytic activity of metacyclics damages the cardiac valve of the sand fly feeding system leading to reflux of the bloodmeal (regurgitation), which promotes transmission by delivering the metacyclics. Vector-born molecules can not only modulate parasite differentiation but also affect the subsequent mammalian infection (see section bellow). Neverthless the uninfected sand fly bites can protect mice from $L$. (L.) major infection [153].

\section{PARASITE DEVELOPMENT IN THE VERTEBRATE HOST}

Leishmania parasites display a complex repertoire of escape mechanisms and strategies that permit the survival in the diverse and often harsh environments of the vertebrate host despite its defense arsenal $[55,155,156]$.

The Leishmania prime infection takes place with the introduction of metacyclic promastigotes during the sand fly bloodmeal. The insect mouthparts lacerate the dermal tissues and superficial vessels of the vertebrate host producing a small hematoma or "blood pool" where the promastigotes are introduced. Besides phlebotomine bite, direct contact [7], blood transfusion [164, 282], hemodialysis [179], organ transplantation [32, 207], congenital [106] and even sexual [300] transmission were also reported.
Components of the phlebotomine saliva and/or salivary gland extracts promote the infection outcome [306]. The saliva exacerbates experimental leishmaniasis by inhibiting microbicidal responses $[135,323]$, antigen presentation [305] and positively regulating the deleterious Th2 activity while down-modulating the protective Th1 responses [185, 311]. Most of the salivary components have not been identified but all sand fly saliva contains ATP/ADPase apyrase that still awaits for determining its function during transmission. Lutzomyia longipalpis saliva contains among other molecules the peptide maxadilan, a potent vasodilator that inhibits pro-inflammatory events in the host, including splenocyte proliferation, delayed-type hipersensibility and TNF$\alpha$ production and induces IL-6 and IL-10 synthesis [242, 285]. These properties suggest a role for maxadilan in the pathogenesis of leishmaniasis, inhibiting immune response at the site of parasite inoculation. Nevertheless, other phlebotomine species saliva devoid of maxadilan also modulate immune functions. The saliva of both $\mathrm{Lu}$. longipalpis and $P h$. papatasi present protein phosphatase (PP)-1/2A activities [159]. Although the diminished iNOS gene expression in macrophages exposed to $P h$. papatasi salivary gland extracts was attributed to these PPase activities [323], the factor responsible for this inhibition is probably the purine nucleoside adenosine [159]. The saliva of Lu. longipalpis which lacks adenosine is unable to inhibit the production of NO in murine macrophages. Adenosine mediates a number of cell functions through interaction with purinergic receptors and may be relevant to the establishment of leishmanial infection as it was shown to reduce neutrophil recruitment and inflammatory responses [70]. Leishmania parasites are transmitted to their vertebrate hosts by infected phlebotomine sand fly bites. Interestingly, prior exposure of mice to uninfected sand flies confers protection against leishmaniasis, associated with strong delayed-type hypersensitivity responses and with interferon- $\gamma$ production at the site of parasite delivery [155]. Immunity is conferred mostly by a 15 $\mathrm{kDa}$ antigen which is being tested in vaccine trials in murine models of leishmaniasis [26, 311].

An early and often transient papular granulomatous lesion termed leishmanioma may be observed in the site of the insect bite. Visceral leishmaniasis (or kalazar $=$ black fever) is caused by the species of the L. donovani complex, i.e. L. (L.) donovani and $L$. (L.) infantum in the Old World and $L$. (L.) chagasi in the New World. The parasites reach many organs via lymph and blood vessels, especially spleen, liver and bone marrow. Patients may experience fever, hepatosplenomegaly, diarrhea, cough, emaciation, anaemia, lymphadenopathy and pancytopeny. Trombocytopeny may lead to hemostatic disorders such as epistaxis and intestinal hemorrages that together with concurrent infections such as pneumonia and sepsis comprise the major causes of death. This form of the disease may pose mortality rates approaching $100 \%$ if untreated and up to $15 \%$ among properly treated patients [91]. The drugs of choice are costly, parenterally administered, generally associated with severe side effects and progressively confronted with resistant parasites [15], therefore the search for new leishmanicidal compounds is urgently required. After the visceral infection resolution a post-kalazar dermal leishmaniasis may be observed particularly in India. 
The cutaneous leishmaniasis is mainly caused by $L$. $(L$.) tropica, L. (L.) major and L. (L.) aethiopica in the Old World and in the New World by species of the L. mexicana complex, i.e. L. (L.) mexicana, L. (L.) amazonensis and $L$. (L.) pifanoi; and the L. braziliensis complex, i.e. L. (V.) braziliensis, L. (V.) guyanensis, L. (V.) panamensis. L. (L.) amazonensis and $L$. $(L$.) aethiopica can also produce the diffuse form of the disease with numerous disseminated lesions often refractory to chemotherapy [324]. The infection by species of the L. braziliensis complex may lead to mucous membrane metastases particularly to the oronasopharyngeal mucosae with the frequent destruction of the nasal septum.

In the mammalian host the parasite proliferates in mononuclear phagocytic cells, mostly macrophages. Once in the human, blood natural antibodies particularly of the IgM class may recognize the promastigotes, activate the classical complement pathway and bind to erythrocyte CR1 [98]. It was also shown that attachment to red cells protects promastigotes from complement-mediated lysis and that promastigotes are transferred from erythrocytes to leukocytes. Realtime kinetics analysis showed that $2.5 \mathrm{~min}$ after serum contact, $90 \%$ of the promastigtes are destroyed [reviewed in 99], implying that during the early transmission period, human complement exerts a strong selective pressure on parasites. They must enter a permissive host cell rapidly to avoid lysis. In the ex vivo model developed by these authors the parasites were ingested by polymorphonuclear leukocytes (PMN), monocytes and eosinophils in the same proportion found in the human blood implying no preferential target cell in this phase. Neverthless, it is accepted that parasites uptaken by PMNs and eosinophils are usually rapidly destroyed [230, 235, 317]. Recent reports however have shown that Leishmania ingested via opsonin-independent mechanisms remain viable in human PMNs [170]. This silent entry may enable evasion from oxidative burst. Promastigotes can also recruit human PMNs by releasing a chemotactic factor [321]. Leishmania blocks the production of interferon gamma (IFN- $\gamma$ )-inducible protein-10 (IP-10) by PMNs [57], inhibiting recruitment and activation of other immune cells such as NK and Th1 T cells. PMN are short-lived circulating cells but once infected by Leishmania, its life span is extended by inhibition of caspase 3 activity [2]. The delay of 2-3 days in apoptosis enables infected PMNs to secrete macrophage inflammatory proteins (MIP) $-1 \alpha$ and $-1 \beta$ resulting in a second wave of phagocytes to the site of infection. The apoptotic PMNs harbouring viable amastigotes are then rapidly engulfed by macrophages, which become inactivated [reviewed in 168].

Langerhans cells may either prime naive $\mathrm{T}$ cells in the drainning lymph nodes or act as parasite reservoirs for sustained immunological memory [195]. Defects in signaling of the epidermal cells can result in failure to overcome infection and development of pathology.

Laminin (LN), a major extracelular matrix (ECM) glycoprotein present in basement membranes is strongly recognized by a $67 \mathrm{kDa}$ membrane laminin-binding protein (LBP) which differs from its mammalian counterpart [16, 120]. LBP binds LN through the YIGSR site on the B1 chain [17]. LN binding through LBP initiates tyrosine phosphorylationdependent signaling in the parasite, which may mediate events necessary for parasite homing and establishment of infection. The 115-130 kDa phosphorylated proteins are not characterized but Entamoeba hystolytica undergoes a similar ECM-activated signaling that increases invasiveness [231]. It is possible that this class of proteins may correspond to focal adhesion kinase-like molecules. LN binding certainly contributes to parasite evasion from the immune system and invasion into host cells.

It is intriguing to think that whereas less than 100 promastigotes are transmitted during phlebotomine probing and as only as $10 \%$ remain alive after a few minutes in contact with human serum elements, parasites still find permissive blood monocytes (approximately $7 \%$ of the blood leukocyte population) in which to multiply. This suggests that most inoculations may be unsucessful. Still more than 2 million people get infected every year [91].

Upon inoculation promastigotes undergo morphological and biochemical modifications including gene expression due to heat shock and differentiate to the vertebrate-adapted amastigote form in the forming PV, derived from maturation and fusion with endocytic/autophagic organelles. Approximately $30 \mathrm{~min}$ after its formation, it becomes acidified to a $\mathrm{pH}$ of 4.5-5.5. This harsh microenvironment is overcome by the action of a parasite membrane $\mathrm{H}^{+}$-translocating ATPase that maintains the leishmanial cytoplasmic $\mathrm{pH}$ at neutrality [123]. The proton electrochemical gradient created across parasite membrane drives the active transport of glucose and proline [122], essential to parasite survival. The full differentiation from promastigote to amastigote stage takes approximately 2-5 days to complete depending on the Leishmania species. The molecular basis undelying parasite differentiation is poorly understood, however heat shock protein 90 (HSP90) was ascribed as playing a pivotal role in this process. Studies carried out in both promastigote and amastigote forms identified 31 proteins present only in the former [31]. The expression of about 65 proteins increase during heat-induced differentiation in vitro while four proteins are decreased late in this process. Mass spectrometry and peptide mass fingerprint revealed that most of this stagespecific proteins code for essential proteins (stress response, cytoskeleton, energy and aminoacid metabolism, signaling and cell cycle).

The PV varies from tight and small to large and loose vacuoles containing from one to 10 or more amastigotes which can be tightly bound to the inner membrane face of the PV via the posterior pole [29] in species such as $L(L$. amazonensis, L. (L.) mexicana, L. (L.) pifanoi. Some of the characterists exhibited by host cell lysosomes and late endosomes are retained by the $\mathrm{PV}$, such as enrichment of lysosome-associated membrane proteins LAMP-1/2, Rab7, macrosialin and cation-independent mannose-6-phosphate receptor. It was reported that $L$. (L.) amazonensis infection results in depletion of macrophage lysosomes $[18,19]$. The acquisition of acidic hydrolases and MHC class II molecules occurs more slowly [reviewed in 10]. It should be stressed out that significant differences in lysosome fusion rates are expected to occur among Leishmania species, generating the great diversity in the size of PV observed.

LPG was also shown to insert itself in the phagosome membrane modifying its properties and preventing the for- 
mation of an inverted hexagonal structure, which results in reduced fusogenic properties [85, 275]. A direct consequence would be steric repulsion between phagosomal and endosomal membranes. Newly internalized promastigotes are able to impair the translocation to phagosomes of the GTPase Rab7, a key molecule for phagosome fusion with late endocytic organelles [275], which confers an early endosome-like compartment milieu for at least a few hours [reviewed in 101]. Once transformation to amastigote form is complete the compartment displays typical phagolysosomal properties [261]. This also correlates with the expression of parasite molecules required to sustain survival in the harsh environment of the PV as well as downmodulation of LPG from the amastigote surface allowing maturation of the compartment [85]. Another interesting feature of the Leishmaniacontaining phagosome is its possible ER origin. It was recently reported that ER may be a membrane source for phagosome formation in macrophages but not in PMN [116].

Differences in the biogenesis of the PV harbouring Leishmania were recently described [76]. PV formation was shown to be species- and developmental stage-dependent and the differences occur after the fusion of early phagosomes with late endosomes/lysosomes. The accessibility of proteins to the PV is still controvertial. Russell and coworkers [261] did not observed transferrin targeting to $L$. (L.) mexicana PV but Borges et al. [45] inequivocally demonstrated the presence of this iron-bearing protein in the lumen of the $L$. (L.) amazonensis containing PV as well as within the parasite flagellar pocket and rnegasome-like structures. Acquisition of gold-conjugated LDL was also demonstrated by intracellular amastigotes [196]. Others have also suggested that intracellular parasites have easy access to numerous substances, such as proteins, lipids, nucleic acids and polysaccharides and even MHC molecules [10, 261]. The presence of parasite ecto-enzymes such as 3'- and 5'nucleotidases/nucleases, acid phosphatase and gp63 may take part in nutrient uptake and metabolism in the PV.

Inside the mammalian host, there is a slow multiplication phase of Leishmania amastigotes (weeks to years). In VL and DCL, accumulation of infected macrophages in the spleen, liver and skin, respectively, can be observed. During this chronic phase of the disease continuous releasing of amastigotes in the infected organs due to rupture of infected macrophages takes place, but little or no protective immune response is triggered. Some authors have suggested that programmed cell death might play a role in silencing of the host immune response. It was shown that uptake of apoptotic $\mathrm{T}$ lymphocytes by macrophage infected with $T$. cruzi increases parasite growth inside these macrophages [113]. Uptake of apoptotic $T$ cells renders the macrophages refractory to inflammatory cytokines. Amastigotes were shown to mimic apoptotic cells by exposing phosphatidylserine (PS) on the cell surface [114]. Recognition of PS moiety is a major mechanism of non-inflammatory particle removal by phagocytes and triggers TGF- $\beta$ secretion, IL-10 production, inhibition of NO synthesis thus enabling parasites to evade killing. Stationary promastigotes also contain significant amounts of PS on their surface, whose partitioning in the two-halves of the membrane bilayer is regulated by ATPdependent out-to-in and ATP-independent in-to-out PS translocases [307].
Moreover, LV patients present increased levels of soluble Fas and FasL, which lead to T cell apoptosis and unresponsiveness $[80,104]$. This may explain, at least in part, the low $\mathrm{T}$ cell responses found in patients with anergic forms of leishmaniasis. In parallel, apoptosis is inhibited in infected macrophages [198], sustaining for longer periods the rapid parasite replication observed in these forms of the disease. In the cutaneous model however increased FasL expression in $L$. (L.) major-infected macrophages synergize with IFN- $\gamma$ to activate leishmanicidal responses and control infection [58, 71].

\section{PROMASTIGOTE INTERACTION WITH HOST CELLS}

Promastigote entry into macrophages is accepted to be a polarized event with most species adhering preferentially via the flagellum, except for $L$. (L.) donovani that shows no specific binding orientation [252]. Nevertheless $L$. (L.) amazonensis infection by the cell body was reported [76]. Leishmania binding to macrophages may be influenced by parasite surface charge [270] and surface free energy [281].

Several ligand-receptor systems have been implicated in the promastigote binding to macrophages. Receptor redundance is a major characteristic of this process, in which several ligands may be recognized by few receptors that may act cooperatively to promote efficient uptake.

Complement receptors (CRs) apparently play a major role in the uptake of different Leishmania species and may be more relevant in the uptake of $L$. (L.) major than in that of L. (L.) amazonensis [203]. There are three receptors that potentially mediate $\mathrm{C} 3$-dependent phagocytosis, CR1 (CD35) and CR3 (Mac-1, CD11b/CD18, $\left.\alpha_{M} \beta_{2}\right)$ that recognize respectively $\mathrm{C} 3 \mathrm{~b}$ and $\mathrm{C} 3 \mathrm{bi}$ and $\mathrm{CR} 4(\mathrm{p} 150,95)$. The relative roles of $\mathrm{CR} 1$ and $\mathrm{CR} 3$ in adhesion and uptake of Leishmania are controversial. CR1 has been proposed to be the primary receptor involved in recognition of complementopsonized parasites but others have argued that CR1 may play a secondary role by cooperating with CR3 and even Fc $\gamma \mathrm{R}$ in the endocytosis of $L$. (L.) major by human macrophages [258]. CR3 was suggested as the major receptor in $L$. (L.) donovani [201] and L. (L.) mexicana [303] promastigotes phagocytosis. It apparently contributes more efficiently to metacyclics adhesion than CR1 probably due to its factor 1 co-factor activity in C3b-iC3b convertion [258, 298]. The LPS binding site of CR3 might mediate LPG binding directly without the participation of complement [303], neverthless, one can argue that in the absence of serum, binding occurs predominantly via $\mathrm{CR} 3$ as a result of $\mathrm{C} 3$ deposition produced by the macrophage itself. This serumindependent CR3-binding was observed in $L$. (L.) donovani infection [330]. Mosser and coworkers [204] suggested that leukocyte integrins do not support Leishmania binding without the requirement of opsonic complement. In the absence of serum the picture may be quite different and conflicting reports have been published. Da Silva and collegues [81] have shown that CR1 might mediate binding of $L$. (L.) major metacyclics to macrophages. It was suggested that the metacyclic LPG fixes C3 more efficiently than the procyclic molecules [240]. These authors suggest that parasite entry via $\mathrm{CR} 1$ may be more advantageous for intracellular survival 
as it does not trigger oxidative burst [81]. The distinct LPG structure of procyclics and metacyclics would therefore determine the complement receptor used and the intracellular fate of the parasite. It is possible that CR1 mediates the inital adhesion of $\mathrm{C} 3 \mathrm{~b}$-opsonized promastigotes. As C3b degradation to $\mathrm{iC} 3 \mathrm{~b}$ proceeds, CR1 affinity decreases and may be then replaced by stable adhesion to CR3 as described in other models [298].

Cooperation between CR3 and mannose-fucose receptor (MFR) in binding and ingestion of $L$. (L.) donovani was also shown [38, 329]. Modulation experiments in which either CR3 or MFR had been rendered inaccessible demonstrated that both receptors must be functional on macrophage surface. In this regard, LPG may act not only as a complement acceptor [240] but also binding to lectin-like receptors such as the mannose-fucose receptor [59] supporting the idea of a multifactorial molecule. LPG binds to the acute phase Creactive protein which increases parasite uptake by macrophages [77] and a LPG-associated kinetoplastid protein (KMP-)11 that presents an arginine residue at position 45 post-translationally modified to a $\mathrm{N}^{\mathrm{g}}$-monomethyl-Larginine. This aminoacid is known for its ability to strongly inhibit iNOS in macrophages and other phagocytic cells [reviewed in 23]. KMP-11 release and degradation in the PV would promote parasite survival by both inhibiting NOS and scavenging nitrogen toxic derivatives. Also, the wellestablished role of LPG in inhibition of PKC signal transduction (see bellow) may be relevant to the outcome of the disease. It is important to point out that LPG variability may result in distinct biological roles among species. The $L$. $(L$.) major promastigotes present a thick and dense LPG coat, which is usually associated to increased resistance to complement-mediated lysis conferring stereochemical surface protection from $\mathrm{C} 5 \mathrm{~b}-\mathrm{C} 9$ membrane attack complex [reviewed in 146]. A recent study reported that although $L$. $(L$.) major LPG is important for oxidative resistance [335], complement resistance rely not only on LPG but also on the function of different glycoconjugates. Besides that, $L$. $(L$.) major presents an ecto-protein kinase (LPK) activity [138] that dephosphorylates complement components interfering with its activation cascades [138]. Other Leishmania species may rely on similar mechanisms to avoid complementmediated lysis [78].

Surface expression of gp63 has often been implicated in Leishmania entry as a complement acceptor [260], facilitating C3b degradation [49] and increasing intracellular survival in macrophages [276]. The gp63 can directly bind CR3 [260] and fibronectin (FN) receptors [48] with or without the participation of the SRYD (Ser-Arg-Tyr-Asp) sequence that mimics the RGD (Arg-Gly-Asp) of several extracellular matrix proteins such as FN [287]. Although the direct binding of parasite molecules to macrophage receptors has been widely reported, studies using transfectants indicate that such binding may be of low avidity [200] and complement may be required for promastigote binding [204, 259] as well as promoting parasite survival by modulating the macrophage oxidative burst [202]. ICAM-like molecules have also been implicated in promastigote binding to macrophages [66]

Macrophage invasion via MFR and neoglycoprotein receptors were reported in Leishmania infection. These re- ceptors were associated mainly to $L$. (L.) donovani in vivo clearence from the blood [60] and may be relevant to recognition in the hepatic environment during the early stages of infection. Kuppfer cells in infected mice present a decrease in the number of receptors as assessed by the use of mannose-bearing liposomes [103] and ${ }^{125}$ I-labelled-mannoseBSA [22]. The major ligand of MFR may be gp63 [226]. In the same way, the macrophage receptor for advanced glycosylation end products was shown to play a role in $L$. $(L$. major uptake [205].

The role of these two major promatigote surface molecules (LPG and gp63) may not be essential to the establishment of $L$. (L.) mexicana infection in vivo as for $L$. (L.) $m a$ jor [290]. Mutants lacking either gp63 [140] or LPG [144, $145]$ are able to infect macrophages and induce lesions in $\mathrm{Balb} / \mathrm{c}$ mice similarly as wild-type parasites. The target deletion mutations obtained in these studies are highly specific to these molecules. In both cases the deleted single-copy genes encode enzymes required to gp63 or LPG expression whereas other molecules are not affected. Also, the ability of L. (L.) mexicana deficient in other related phosphoglycan repeat-containing molecules to promote infection is retained [146]. Other groups have earlier reported the occurrence of mutants for these surface conjugates unable to infect, survive and proliferate inside the host cell [e.g. 104, 175, 279]. The precise defects occuring in these mutants however were not fully determined as chemical mutagenesis was reported to induce multiple mutations. Overexpression of gp63 by plasmid complementation results in increased binding to macrophages. This gp63-complemented parasites neverthless present low amounts of nuclear-encoded gp63 protein [175]. Decreased gp63 expression by episomal expression of antisense mRNA also abolished binding to macrophages [65]. Much work has yet to be done in order to inequivocally determine the functional role of these glycoconjugates in Leishmania that will presumably reinforce the great variability among species.

The cooperativity between different receptors may change their apparent ligant affinity. In this regard, it was shown that ligation of FN to CR1 increases C3b-mediated internalization. The promastigote attachment can also be mediated by ECM components such as FN [317, 319, 332], LN [118, 119] collagen [176] and proteoglycans via a heparin-binding activity of the parasite $[50,163]$. It is interesting to point out that heparin may be required as a co-factor for FN binding to macrophages [143, 312] and anti-FN antibody inhibits the promastigote attachment [253]. Promastigote growth in FN-depleted medium reduces parasite uptake, but the addition of exogenous human plasma FN may not promote the promastigote attachment to phagocytes [319, 332] may be due to the FN shedding by the parasites [319]. Interestingly parasite-shed membranes are also ingested by macrophages [270]. Phagocyte spreading on FN-coated substrata may up-regulate the CR activity [251, 331] but decreases the infection by $L$. $(V$.) panamensis [255]. Interaction with FN primes $L s h(\mathrm{r})$ macrophages for enhanced TNF$\alpha$ response to Leishmania parasites in the presence of IFN- $\gamma$ [111].

Conflicting results were reported on the relative role of the humoral immune response in Leishmania promastigote 
entry and the participation of Fc receptors in the host cell infection was widely underestimated. Natural IgM antibodies present in normal human blood fix complement on promastigote surface and consequently those cells form C3bmediated rosettes with red blood cells [98]. These authors stressed the importance of Igs in the early Leishmania infection. Anti-Leishmania antibodies were reported either to enhance [137] or to inhibit [61] binding to macrophages in vitro.

The leishmanial infection may selectively block IL-12 production $[189,249]$. This cytokine is critical in the orchestration of both innate and acquired immunity [297]. Production of the IL-12(p40) heavy chain is stimulated through engagement of CD40 on antigen-presenting cells by its ligand on activated T cells via JAK/STAT. Translocation of phosphorylated STAT1 regulates the induction of IFN consensus binding protein to the IL-12(p40) promoter [reviewed in 189]. Production of IL-12 induces IFN- $\gamma$, which in turn leads to the development of Th1 responses, macrophage activation and production of complement-fixing antibodies. The regulation of IL-12 production is achieved by antiinflammatory cytokines such as TGF- $\beta$, IL-10 and type I IFN as well as prostaglandin E2 (PGE2). Leishmania parasites may take advantage of multiple strategies to subvert IL12 production. One of the best-studied processes is induction of TGF- $\beta$, which is a remarkably important escape mechanism for Leishmania parasites [20]. TGF- $\beta$ plays a pivotal role in Leishmania survival since it can reduce iNOS mRNA synthesis and increase the iNOS degradation [322] as well as enhance arginase activity [46]. In this regard, anti-TGF- $\beta$ treatment blocks $L$. $(L$.) chagasi replication in co-cultures of macrophages and activated CD4+ T cells [126] and promotes healing of $L$. (L.) major lesions [173].

The leishmanial intracellular killing may be attained by both ROI [52] and RNI [130, 210]. NO is relatively unreactive towards biomolecules; however it easily combines to $\mathrm{O}_{2}{ }^{-}$ to form the highly reactive species, peroxynitrite. Peroxynitrite oxidazes and nitrates a variety of biological molecules and is thought to be the main mediator of NO effects. For Leishmania, NO is solely cytostatic whereas peroxynitrite is cytotoxic $[11,172]$. In resistant mice, Leishmania infection is debeled upon activation of NO synthesis nearby the PV, a suitable site for peroxynitrite formation due to NADPH oxidase proximity. This limits peroxynitrite scavenging before it targets the intracellular parasite. An elegant study by Linares and coworkers [172] showed that peroxynitrite reacts with macrophage carbon dioxide generating carbonate radical and nitrogen dioxide increasing efficiency of protein tyrosine nitration [180, 181, 269]. Decomposition of peroxynitrous acid to hydroxyl radical and nitrogen dioxide also occurs.

Parasites evolved mechanisms similar to those found in mammalian cells to avoid toxic free radical damage. These mechanisms involve the participation of thiol-presenting molecules such as trypanothione [102, 256, 309] and polyamines (PAs) [113, 134, 225]. Leishmania trypanothione, a glutathione-spermidine conjugate, takes part in a thiol-redox cycling system. Trypanothione is involved in the proposed mechanisms for sequestration of reduced antimony $\mathrm{Sb}$ (III) $[115,117]$ which is then extruded from the parasite via specific transporters of the ABC family [134].
Oxidative stress resistant parasites usually present increased ornithine decarboxylase expression and so high putrescine and spermidine levels. These PAs play major roles in parasite resistance and growth thus offering interesting targets to drug development. Polyamine biosynthesis inhibitors show effective results in sleeping sickness $[13,14$; 186], inhibit trypanothione reductase [225], which is an essential enzyme for Leishmania survival [309] and also lead to mitochondrial destruction [268; Valentim et al. submitted]. Interestingly, PAs have also a protective role in the redox organelles of trichomonad parasites [250]. The arginase activation during leishmaniasis may switch the Larginine metabolism towards ornithine and PA generation rather than NO production [148].

\section{AMASTIGOTE INTERACTION WITH HOST CELLS}

The difficulty in obtaining large amounts of purified amastigotes has long hampered studies with this form. The development of axenic amastigote cultivation procedures $[132,227]$ allowed a growing number of approaches using this stage in the last decade. These parasites are often referred to as amastigote-like and many reports indicate differences in the expression of some molecules but they also share many cellular, biochemical and molecular similarities as well as the capacity to infect and proliferate within macrophages [24, 100, 142, 228, 243]. The differences do not invalidate axenic amastigotes as tools for understanding Leishmania infection and in vitro grown promastigotes also display differences as compared to the insect-born ones.

Comparatively little is known about the uptake of Leishmania amastigotes as compared to the infection by promastigotes. As for promastigotes, the relative importance of the receptor-ligand systems may vary among species but yet no intrinsic ligand on the amastigote surface has been inequivocally identified. Although the main promastigote surface molecules LPG and gp63 are present in low levels or absent from amastigote surface, LPG was shown to inhibit $L$. (L.) major amastigote binding to macrophages indicating the participation of lectin-like receptors [160]. A heparinbinding activity of $L$. (L.) amazonensis amastigotes was described by Love et al. [178], which may mediate binding to heparan sulfate proteoglycans. This may account for the amastigote recognition by other cell types. FN can also mediate amastigote binding [332].

Like the promastigote form, amastigotes are able to undergo rapid, C3b-mediated erythrocyte binding (vide supra). The relative role of CRs on amastigote internatization is neverthless controversial. It was suggested that a proportion of $\mathrm{C} 3$ binding to amastigote surface may be via noncovalent linkages and therefore may not be in the suitable conformation to mediate binding to CR3 [330]. The amastigote binding was studied in fibroblasts transfected with macrophage receptors [232]. This elegant approach poses the advantage of testing individual receptor kinds but must be carefully interpreted since the possible cooperation between these receptors and ECM receptors are unknown and different cell types may display distinct endocytic machineries and different abilities to mobilize surface receptors thus triggering different cytoskeleton-dependent responses. In this way, transfection of CR3 to the fibroblast-like COS cells does not 
render these cells susceptible to infection [232] but blockage of CR3 inhibits binding to macrophages [133]. Mosser and Rosenthal [203] stated that $L$. (L.) amazonensis amastigotes do not bind specifically to the mannose receptor or to CRs. Differently, L. (L.) major internalization occurs mainly through CR3 and FcR but other receptors may also be involved since the B cell-deficient SCID mice are equally susceptible to L. (L.) major infection [133].

The uptake of $L$. (L.) amazonensis and $L$. (L.) mexicana amastigotes is promoted by specific antibodies but not by normal serum [161]. Lesion-derived amastigotes are Igopsonized and so probably rely on FcR-mediated entry in vivo. The absence of circulating antibodies affects the development of cutaneous lesions in amastigote-initiated infections but not when promastigotes are used since other opsonins and surface molecules are implicated in promastigotemacrophage interaction [161]. Contrary to CRs, FcRs are known for their ability to activate the small GTPase Rac, which is essential in the assembly of NADPH oxidase. Yet amastigotes poorly activate oxidative responses and cytokine production [63, 189]. Engagement of FcR specifically induces the production of IL-10, rendering macrophages refractory to IFN- $\gamma[156]$ and decrease TNF- $\alpha$ and IL-12 production [143]. IL-10 is sufficient to completely inhibit transcription of both IL-12(p40) and IL-12(p35) genes in macrophages [189]. In non-professional phagocytic cells, entry involves activation of Rho and cdc42 but not Rac-1, responsible for triggering oxidative defenses in these cells [196]. Rac-1-independent phagocytosis of Ig-coated amastigotes by cells lacking opsonin receptors may be responsible for parasite persistence in vivo.

Leishmania amastigotes secrete a non-filamentous proteophosphoglycan (aPPG) in the extracellular medium and within the PV, which is highly efficient in inducing macrophage vacuolization being probably involved in the formation and enlargement of the huge PV induced by the species of the L. mexicana complex. This molecule shares carbohydrate structures with the promastigote LPG and APPG and was first identified in mouse lesions caused by $L$. (L.) mexicana. The concentration of aPPG in the PV may accumulate to $\mathrm{mg} / \mathrm{mL}$ range. It was believed that $\mathrm{aPPG}$ was secreted solely by Leishmania species that induce large vacuoles but it was also identified in $L$. (L.) major and $L$. (L.) donovani amastigotes [233]. The mechanism of large vacuole formation was suggested to rely on the polyanionic nature of the aPPG, which may facilitate fusion by charge interactions modulating membrane fluidity and fusion [reviewed in 146]. Secreted aPPG was suggested to activate complement via the mannose-binding lectin pathway and thus exhaust the complement system locally protecting amastigotes from lysis [146]. In addition, C3a and C4a peptides generated could recruit circulating monocytes to the site of infection. The aPPG is highly resistant to proteolytic degradation impairing its presentation and thus it is neither recognized by $\mathrm{CD} 4^{+} \mathrm{T}$ cells nor elicits B cell responses [1, 146].

Other highly glycosylated secreted molecules were described in the amastigote form. $L$. (L.) donovani amastigotes synthesize and secrete a conserved acid phosphatase activity (SAP) both in vitro and in vivo [105]. It was suggested that the presence of anti-SAP antibodies in the serum of Kalazar patients might indicate a role for this enzyme in the survival of the parasite within the human host. The search for a similar molecule in $L$. (L.) mexicana and $L$. (L.) amazonensis amastigotes neverthless failed. SAP is believed not to be synthesized by intracellular amastigotes of these species [reviewed in 146] and deletion of Imsapl/2 genes proved this enzyme is not essential to $L$. (L.) mexicana infectivity and survival [327]. Nevertheless, a SAP-like enzyme can be detected in vitro using isolated and axenically cultivated $L$. (L.) amazonensis amastigotes [Martiny et al. submitted]. It is suggested that this enzyme may have a role in early deactivation of macrophages by this parasite [182].

The arrangement of the SAP genes includes an intergenic region that was shown to confer a lesion growth phenotype. This intergenic region between SAP1 and SAP2 genes codes for a $41-45 \mathrm{kDa}$ protein homologous to mitogen-activated protein (MAP) kinase (LMPK). It is expressed in both $L$. (L.) mexicana developmental stages but its function is restricted to the intracellular form, suggesting that it undergoes posttranslational modifications [327]. Its high homology to members of the MAP kinase pathway and presence of all major typically conserved domains suggest it is involved in cell division. LMPK homologues are present in many Leishmania species implying that it can be required for parasite survival and thus comprise a suitable target for chemotherapy intervention.

\section{SIGNAL TRANSDUCTION IN THE LEISHMANIA- INFECTED MACROPHAGES}

There are several reports now suggesting the interference of a multitude of cell signaling networks in Leishmaniainfected macrophages [reviewed in 247, 313]. Here we will enphasize the well-known protein kinase $\mathrm{C}$, calcium and tyrosine kinase related pathways.

Leishmania infection interferes with protein kinase Cmediated pathways and decreases protein phosphorylation of host cell proteins induced by phorbol ester [200, 221]. The translocation of PKC isoforms in $L$. (L.) major-infected macrophages revealed a differential kinetic response to the phorbol ester PMA. PKC $\alpha$ translocates to the membrane with a peak accumulation in approximately $15 \mathrm{~min}$ but its degradation is delayed as compared to uninfected cells. The PKC $\beta$ translocation occurs with similar kinetics but degradation was reduced in approximately 2.5 -fold. The prolonged association of these PKC isoforms may ensure inhibition of membrane-bound enzymes. Infection had little effect on translocation, distribution and degradation of PKC $\delta$. In absence of PMA stimulation none of the PKC isoforms is translocated in response to attachment or internalization of Leishmania parasites [237]. Parasite LPG was implicated in deactivation of macrophages [88]. It was shown that purified LPG inhibits PKC $\alpha$ isolated from rat brain in a cell-free system $\left(K_{\mathrm{I}}<1 \mu \mathrm{M}\right)$. LPG does not significantly inhibit $\mathrm{PKC} \alpha$ binding to membranes but reduces its activity by $70 \%$ despite being on opposing sides of the bilayer. Most likely LPG may alter the physical properties of the membrane by increasing stability [121], disrupting the PKC activation stoichiometry [27] and reducing its sensitivity to diacylglycerol (DAG), the physiological activator of most isoforms of PKC. Insertion of LPG molecules into the 
membrane bilayer raises its transition temperature regardless of its leaflet position (outer and/or inner) hampering protein rearrangements and inhibiting membrane fusion [192, 244]. This is opposite to the effect caused by DAG, which destabilizes the bilayer $[121,192]$. Of note PKC activity is associated with $\mathrm{CR} 3$ and FcR functioning. Leishmania interacts with both receptors and LPG is acceptor of C3 [303]. LPG also inhibits PKC activity in intact macrophages, preventing the phosphorylation of substrates such as myristoylated alanine-rich $\mathrm{C}$ kinase substrate (MARCKS) protein in response to DAG [74, 87]. During infection LPG is transferred to macrophages and can be found intact in both vesicles and cell surface [308] during the first day post-infection but is no longer detected after five to six days. It was suggested that the lipid moiety of the LPG molecule, which consists of both saturated unbranched $\mathrm{C}_{24}$ and $\mathrm{C}_{26}$ hydrocarbons, would be the primary responsible for the suppressed PKC activity [190] but it is noteworthy that purified LPG preparations may display a peptidic contaminant [149]. However recent studies employing synthetic LPG fragments have produced similar effects on macrophage function. LPG-deficient promastigotes [191] and amastigotes (which do not synthesize LPG but the glycosylinositolphospholips [GIPLS; 187] are also able to impair PKC-mediated events. PKC from amastigote-infected monocytes requires a two-fold increase in DAG concentration in order to achieve half-maximum activation and unlike infection by promastigotes; translocation of the enzyme to the membrane bilayer is blocked [221, 301]. Leishmania GIPLs pertain to the glycosylphosphatidylinositol (GPI) family of molecules, which are structurally related to phosphatidylinositol (PI) but presenting high level of variation in fatty acid composition and side-chain modifications to the conserved glycan core. GIPLs are present in high copy numbers and may cover up to $80 \%$ of the amastigote cell surface. An important feature of this molecule is the preponderance of alkylacylglycerols within the lipid domain. The L. (L.) mexicana GIPLs antagonize PKC and $\mathrm{NF}-\mathrm{kB} / \mathrm{c}-$ rel activation downregulating macrophage responses to diverse stimuli $[301,302] L$. (L.) major GIPL null mutants however retain their ability to inhibit host cell signaling [301, 302].

Different isoforms of PKC have been implicated in several cell functions such as induction of inflammatory mediators, expression of MHC-class I and class II genes [171, 284], initiation of oxidative burst [328] and apoptosis [271, 328]. They also convey signals from the cell surface to the nucleus by activation of downstream pathways such as MAP kinases [68]. In macrophages, PKC-dependent signal transduction triggered by bacterial LPS is initiated by activation of phospholipase C (PLC) and hydrolysis of phosphoinositol-4,5-bisphosphate (PtdIns4,5P2) into inositol triphosphate $\left(\mathrm{IP}_{3}\right)$ and DAG $[27,154]$. As a result of PKC activation, protein phosphorylation and rapid expression of "early competence" genes such as $c$-fos occur. In macrophages, $c$-fos gene expression represents a PKC activation marker since the increase in its mRNA levels is tightly linked to this enzymatic activity. The $c$-fos gene product functions as a nuclear third messenger coupling signals elicited in the cell surface into phenotypical long-term alterations by regulating the expression of target genes [139]. Leishmania is able to inhibit both PKC-mediated $c-f o s$ and tnf gene expression [86,
87, 198]. The thf gene expression inhibition by L. (L.) donovani parasites probably relies on perturbation of prostanoid synthesis by macrophages. It was shown that Leishmania infection induces increased PGE2 levels [108, 248] and PGE2 downregulates thf gene expression in macrophages [53]. In this regard, indomethacin abrogates Leishmaniainduced impairment in thf gene expression [86]. Conversely, impairment of LPS-induced c-fos expression is suggested to be achieved by disturbance of DAG stimulation of PKC by Leishmania-derived LPG [89]. LPG seems to selectively inhibit PKC-mediated signal transduction. In vitro studies demonstrated no significant inhibitory effect of LPG or intact $L(L$.) donovani parasites on $c$-fos expression induced by dibutyril cAMP, confirming that it does not act on PKAassociated signaling $[89,198]$ which is in agreement with the fact that PKA pathways are considered inhibitory whereas PKC-dependent signaling activates macrophage effector mechanisms [67]. Impairment of PKC pathways can increase Leishmania infection levels. Marcophage PKC inhibition by $\mathrm{H} 7$, staurosporine or prolongued PMA treatment augment parasite burden $[183,198]$. Earlier, it was shown that depletion of PKC activity by long-term PMA treatment abolishes the ability of macrophages to overcome $L$. (L.) donovani, Toxoplasma gondii and Trypanosoma cruzi infections by inhibiting the release of toxic oxygen species such as $\mathrm{O}_{2}{ }^{-}$and $\mathrm{H}_{2} \mathrm{O}_{2}$ [209]. On the other hand, studies using cytochalasin Dtreated macrophages demonstrate that $L$. (L.) donovani promastigote binding triggers a rapid and transient redistribution of PKC isoforms although the overall activity is depressed as compared to uninfected cells stimulated with PMA [37], which is in accordance to previous data [221]. After infection, signaling is switched off and PKC signaling impaired suggesting that early activation of PKC may be involved in signaling required for phagocytosis of the parasite. In this regard, PKC regulates actin polymerization during phagocytosis and was reported to be translocated to the IgG-coated beads-containg phagosomes of human monocytes and PKC antagonists inhibit phagocytosis dose-dependently [reviewed in 131]. Cross-linking of Fc $\gamma \mathrm{R}$ induces the translocation of PKC isozymes $\alpha, \beta, \varepsilon, \delta$ and $\xi$ [334]. FcR ligation was also implicated in IL-10 production by macrophages that may be responsible for suppression of macrophage effector functions. Furthermore, IL-10 inhibits $\mathrm{Ca}^{2+}$-dependent PKC in the same way as L. (L.) donovani infection [36]. PKC is essencial for the induction of proinflammatory cytokines. Defective PKC activity was described in $L$. ( $L$.) donovani and $L$. (L.) amazonensis infections both of which may cause severe anergic manifestations in the host. Anergy is associated to IL-10 production attenuating host defense mechanisms and favoring disease progression [156]. The FcRmediated IL-10 production probably acts reinforcing the impairment of signaling events in the infected macrophages. PKC downmodulation seems to be relevant for parasite survival [293]. An overexpressing dominant negative PKC $\alpha$ mutant macrophage cell line is permissive to infection of both wild-type and LPG-defective promastigotes suggesting a critical role of this isozyme in the macrophage function against intracellular Leishmania. Increased survival in these cells cannot be attributed to impaired oxidative burst or nitric oxide production [293]. The endogenous PKC substrates MARCKS and MARCKS-related protein (MRP) are involved in the regulation of cortical actin cytoskeleton rear- 
rangement, participating in phagocytosis and membrane trafficking in macrophages $[6,174]$. Both are down-regulated in $L$. (L.) major-infected macrophages, due to proteolytic degradation by the parasite surface metalloproteinase gp63 $[74,75]$. A soluble form of gp63 was described [47] and may account for this activity. Proteolysis of these molecules may be relevant for parasite infection and survival facilitating internalization via proteolytically-generated peptides corresponding to the effector domains of MARCKS and MRP. Both peptides induce more intense actin polymerization than the intact proteins. On the other hand, depletion of MARCKS may help circunvent PKC-mediated maturation of phagosomes [6]. Indeed, $L$. (L.) donovani PV exhibits poor fusogenic properties and it was reported that Leishmania impair phagosome maturation after internalization [90].

Several genes have been shown to be involved in the resistance/susceptibility phenotype to leishmaniasis. The nramp gene (previously designated Bcg/Lsh/Ity) also involved in the control of Mycobacteria and Salmonella infections codes for an integral membrane protein termed natural resistance associated macrophage protein (NRAMP) 1, targeted to Lamp1-rich phagosomes [28]. Differences in PKC activity are observed in resistant and susceptible macrophages. The macrophage PCK from resistant mice present an enhanced phosphorylation activity over endogenous substrates which does not correlate with differences in phorbol ester receptors and is less sensitive to DAG activation [222]. These results suggest that genetic control of infection under Lsh locus may be associated to defective PKC activity.

Changes in intracellular $\mathrm{Ca}^{2+}$ serve as a coupling factor or second messenger that mediates signal transduction, controlling several cell functions. $\mathrm{Ca}^{2+}$ signaling in the host cell can be subverted by Leishmania, promoting disease establishment; attachment of Leishmania parasites to macrophage receptors is $\mathrm{Ca}^{2+}$ - and temperature-dependent [194]. $\mathrm{Ca}^{2+}$ is an essential co-fator for binding of mannose-or glucosecontaining glycoconjugates to the lectin concanavalin A. It was proposed that depletion of extracellular $\mathrm{Ca}^{2+}$ may influence receptor-ligand binding required for parasite entry. $\mathrm{Ca}^{2+}$ participates in $L$. (L.) donovani attachment to macrophages as assessed by the use of $\mathrm{Ca}^{2+}$ ionophore and the channel blockers verapamil and nifedipine [117, 194]. Elevation in $\left[\mathrm{Ca}^{2+}\right] \mathrm{i}$ promotes Leishmania attachment and probably renders the macrophage unresponsive to extracellular stimuli transduced by $\mathrm{Ca}^{2+}$ mobilization. Macrophage $\left[\mathrm{Ca}^{2+}\right]_{i}$ is raised by two main mechanisms, mobilization from intracellular stores such as ER and sequestration from the extracellular millieu via $\mathrm{Ca}^{2+}$ channels. The parasite LPG binds $\mathrm{Ca}^{2+}$ ions providing a microenvironment poor in free $\mathrm{Ca}^{2+}$, suitable for intracellular $L$. (L.) major amastigote proliferation $[105,117]$. Increased in $\mathrm{Ca}^{2+}$ concentration in the vicinity of the parasite, caused by the ion inlux, may regulate cell division [326]. Increased $\mathrm{Ca}^{2+}$ in the PV may also be beneficial to parasite as it has been associated to MDR phenotype [129]. In fact, $\mathrm{Ca}^{2+}$ channel blockers were shown to reverse L. (L.) donovani resistance to taxol [157].

Differently from Trypanosoma cruzi, Leishmania induces a sustained $\left[\mathrm{Ca}^{2+}\right]_{\mathrm{i}}$ elevation which slowly reaches a plateau and is thought to be mostly due to increased permeability of $\mathrm{Ca}^{2+}$ channels rather than release from intracellular stores, since $\mathrm{IP}_{3}$ generation is significantly attenuated in these cells [220]. Although PtdIns4,5P2 levels are reduced by approximately $54 \%$ in infected cells, it cannot account for the abrogated $\mathrm{IP}_{3}$ generation. These cells are refractory to extracellular stimuli such as fMLP, producing virtually no ROI [220]. Host cell unresponseviness could also result from the dephosphorylation of PtdIns4,5P2 and $\mathrm{IP}_{3}$ by tartrateresistant Leishmania AcP in vitro [79] or translocation of a parasite phosphatase to the host cell cytoplasm as demonstrated for Yersinia YopH PTPase [40] that impairs host cell responses. In this regard it is noteworthy that both promastigotes and amastigotes present a perforin-like hemolysin or leishmaniolysin [217]. Some authors have suggested that parasites may inhabit the host cell cytoplasm [252], but such cytoplasmic localization was not inequivocally demonstrated. In this case, parasite surface molecules would be in direct contact with the macrophage signal transduction machinery. Alternatively, elevated $\left[\mathrm{Ca}^{2+}\right]_{\mathrm{i}}$ could activate $\mathrm{IP}_{3}$ phosphatase, resulting in inositol phosphate degradation [165]. Increased concentrations of cytosolic free $\mathrm{Ca}^{2+}$ in infected cells may also promote activation of $\mathrm{Ca}^{+}$-sensitive phosphoprotein phosphatases such as calcineurin (PP2B) and pyruvate dehydrogenase phosphate phosphatase [162]. In fact, an increase in macrophage calcineurin activity was observed following L. (L.) donovani infection [219]. A general dephosphorylation of cellular proteins is observed in macrophages infected with Old [39, 214, 223] and New World Leishmania species [178, 182]. Olivier has suggested that the sustained elevation in $\left[\mathrm{Ca}^{2+}\right]_{i}$ is due to emptying of intracellular stores as a consequence of inactivation of ER ATPase pumps by phosphatases activated during initial parasite interaction. The emptying of $\mathrm{Ca}^{2+}$ stores would induce release of second messengers and opening of $\mathrm{Ca}^{2+}$ channels of the SOC family [219].

Loss of $\mathrm{Ca}^{2+}$ homeostasis leads to down-modulation of the microbicidal response of the infected macrophage [84; $150,241]$ and development of pathology, supporting increased parasite burden [119]. In this regard, treatment of $L$. (L.) donovani- infected Balb/c mice with the $\mathrm{Ca}^{2+}$ channel blocker nifedipine reduces production of oxygen free radicals by macrophages and neutrophils [117]. The ability of Leishmania parasites to interfere with $\mathrm{Ca}^{2+}$ homeostasis seems to be a general mechanism rather than targeted to macrophages, supporting the idea of a pathogenesis mechanism. It was recently demonstrated that erythrocytes from kalazar-ill animals present altered $\mathrm{Ca}^{2+}$ homeostasis leading to modifications in membrane stability. It was suggest that the increased $\left[\mathrm{Ca}^{2+}\right]_{\mathrm{i}}$ might be associated with lipid peroxidation, oxidation of SH groups and a marked degradation of membrane proteins. Decreased membrane thiols turns the erytrocyte membrane more susceptible to $\mathrm{Ca}^{2+}$-activated proteases, which in turn would result in lysis and anaemia, a common symptom of visceral leishmaniasis [277]. A sustained elevation in $\left[\mathrm{Ca}^{2+}\right] \mathrm{i}$ may also prevent the activation of macrophages by endotoxins or by $\mathrm{Ca}^{2+}$ itself since it was shown that $\mathrm{Ca}^{2+}$ transients can mimic IFN- $\gamma$-induced activation of macrophages for intracellular killing, secretion of NO [51] and release of TNF [53].

A growing body of evidence has been recently brought about Leishmania-infected macrophage dysfunctions linked to altered protein tyrosine kinase (PTK)-related pathways. 
Defects in stimulus-response coupling in infected cells leading to impaired functional responses may determine the activation state of the phagocytic cell and the outcome of the disease. Among the key cytokines involved in modulation of immunity, IFN- $\gamma$ is perhaps the best studied. It activates macrophages for enhanced microbicidal activity and for the MHC class II expression. The intracellular signaling in response to IFN- $\gamma$ involves two cytoplasmic PTKs members of the Janus (JAK) family of non-receptor tyrosine kinases. Exposure to IFN- $\gamma$ induces tyrosine phosphorylation and activation of JAK1 and JAK2, which catalyze the phosphorylation of the STAT1 transcription factor. Dimerization and translocation of phosphorylated STAT1 to the nucleus preceeds binding to IFN- $\gamma$-inducible genes and activation of gene transcription. L. (L.) donovani-infected macrophages have suppressed responses for IFN- $\gamma$ [215]. These authors found distinct sets of IFN- $\gamma$-induced tyrosine-phosphorylated proteins. Proteins migrating at 125, 60 and $52 \mathrm{kDa}$ are not affected by Leishmania infection, regardless of the time, suggesting that Leishmania does not inhibit the overall IFN- $\gamma$ signaling. Nevertheless, prolonged infection leads to abrogation of JAK1, JAK2 and STAT1 tyrosine phosphorylation $[21,246]$. This effect cannot be attributed to reduced expression of these proteins and is not observed on Staphylococcus aureus-infected cells, which are fully responsive to IFN- $\gamma$. Activation of JAK-STAT signaling occurs normally in the initial hours of infection, decreasing after $7 \mathrm{hs}$ and completely ceasing after 16 hs [215]. The delay in deactivation may be due to dependency of infection levels or requirement for expression of an inhibitor at appropriate concentrations. A recent study has shown an increase in the expression of supressor of cytokine signaling 3 (SOCS3) in L. (L.) donovani-infected cells [34] which may constitute a regulatory mechanism for IFN- $\gamma$ interfering. SOCS3 partially reduces STAT1 phosphorylation and/or reporter gene activity in mammalian cells [286, 295, 296], associates with tyrosinephosphorylated receptor chains inhibiting STATs binding and phosphorylation [216] and it was suggested that it can bind to JAK1 and JAK2, inhibiting kinase activity.

Early infection $(<1 \mathrm{~h})$ of macrophages with New World L. (L.) amazonensis promastigotes induces tyrosine phosphorylation of several host cell proteins [183]. The overall intensity of tyrosine phosphorylation is higher in macrophages infected with avirulent parasites (in vitro grown for long periods) than with virulent ones (recently transformed from lesion-isolated amastigotes), indicating the loss of possible escape mechanism involved in deactivation. This Leishmania species presents an ecto-phosphatase activity highly sensitive to vanadium derivatives, which may account for this phenomenon. Parasite- [182, 183, 314] and/or hostderived phosphatase activities $[39,214]$ are potential candidates to disrupt PTK-linked pathways. Possibly, these mechanisms take place simultaneously. Macrophages infected with $L$. (L.) amazonensis amastigotes present diminished tyrosine phosphorylation in response to LPS or zymosan [182]. Downmodulation of macrophage responses to extracellular stimuli may be quite relevant in the opportunistic infections concurrent with leishmaniasis. Inhibition macrophage responses may be produced by amastigote crude extracts but not by unviable parasites [178, 182] or pretreated with PTPase inhibitor sodium orthovanadate, sug- gesting the participation of an ecto-phosphotyrosine phosphatase activity on dephosphorylation of macrophage proteins. The participation of endogenous host cell phosphatase activities was also demonstrated [39, 214, 215]. The induction of two stress-activated phosphoprotein phosphatases PAC-1 and MKP-1 during Leishmania infection was suggested [215]. More recently, Src homology 2 domain (SH2)containing tyrosine phosphatase SHP-1 activity was found to be augmented in $L$. (L.) donovani-infected cells [39, 214]. Nandan and colleagues [213] reported that a $L$. (L.) donovani $56 \mathrm{kDa}$ elongation factor- $1 \alpha(\mathrm{EF}-1 \alpha)$ is exported from the PV and binds to SHP-1 leading to its activation. Strikingly, macrophage EF-1 $\alpha$ is unable to perform such biological activity. The 449 deduced amino acid sequence of parasite EF- $1 \alpha$ showed a number of significant structural and functional changes $(75.5 \%$ identity) as compared to its mammalian counterpart, including absence of a hairpin loop corresponding to a 12 amino acid deletion and substitutions at positions 151-152 [213]. Apparently the Leishmania EF-1 $\alpha$ has tyrosine-phosphorylated motifs which may bind to $\mathrm{SH} 2$ domains in SHP-1. These authors also found redistribution of the host cell EF-1 $\alpha$ in infected cells [213].

The activation and translocation of SHP-1 renders cells refractory to activating signals. SHP-1 induction is associated with MAP kinase, IFN- $\gamma$-triggered JAK2 and expression of $c$-fos and iNOS. MAP kinases are downstream targets of a variety of signaling events including $\mathrm{PKC}$ activation. The inhibition of PKC signaling in infected cells may preclude further activation of this pathway. In fact, the expression of activation genes such as $c$-fos is dependent upon translocation of activated components of the MAP kinases, the extracellular-signal regulated protein kinases (ERK) 1 and 2 . Full activation of MAP kinases is achieved by phosphorylation on tyrosine and threonine residues, which is tightly controlled by a family of dual-specificity enzymes known as MAPK phosphatases. Alternatively, different protein phosphatases may render ERK inactive by dephosphorylating a single residue. Leishmania amastigotes are capable of attenuating LPS- [182] and PMA-induced [214] tyrosine phosphorylation of ERK1. These data indicate that Leishmania is able to impair MAP kinases regardless of the upstream pathway activated. Pre-treatment of both macrophages and parasites with sodium orthovanadate abrogates attenuation of MAP kinase activity, corroborating the participation of parasite and host cell enzymes in this process. It is possible that these enzymes act sequentially to bring about macrophage dysfunction, the parasite enzyme acting at early infection times until triggering of endogenous host cell phosphatases which may maintain anergy to extracellular stimuli during the course of the disease. Of note, immunodepletion of SHP1 from infected cell lysates does not completely abrogate MAP kinase dephosphorylation, supporting the possibility of other phosphatase activities.

The effect on MAP kinase dephosphorylation is selective for the tyrosine residue, since threonine seems to remain phosphorylated [214]. Notwithstanding, tyrosine phosphorylation of multiple proteins induced by LPS [182] but not by PMA [214] was diminished in response to Leishmania parasites. SHP-1 activity seems to be also involved in impaired JAK2 activation triggered by IFN- $\gamma$ [39]. SHP-1 immunoprecipitates of infected cells reveal an increase in 
JAK2-SHP-1 association, a fact previously observed in other cells and associated to a reduction in the activity of the former and an increase in the latter [151]. Although not yet tested, it is possible that SHP-1 may also counteract IFN $\alpha / \beta$ signaling since it was shown to modulate other members of the JAK family.

It is suggested that Leishmania-derived molecules such as GIPLs may modulate SHP-1 activity. The conserved glycan core of Leishmania GIPL was shown to maximally activate p59 $9^{\text {hck }}$ PTK in macrophage lysates [301]. Hck activity is particularly implicated in TNF expression and PPG was shown to inhibit TNF- $\alpha$ production and synergized with IFN- $\gamma$ to trigger the NO release by macrophages [246].

The delay in tyrosine dephosphorylation observed in early infection may be relevant to parasite entry. Several phagocytic receptors are coupled to PTK pathways [reviewed in 131] and increased concentrations of PTK inhibitors decrease $L$. $(L$.) amazonensis promastigote adhesion to and internalization by macrophages [179]. Conflicting results are nevertheless reported concerning the PTKdependency of amastigote invasion. None of the inhibitors tested by our group presented significant effects on amastigote entry [182], but Love et al. [178] reported a dosedependent inhibition after genistein treatment of macrophages. These divergent results may reflect the distinct methodologies used. Prolonged incubations with genistein [3] affect macrophage spreading pattern down-regulating the overall phagocytic activity. Phosphotyrosine residues accumulated in the vicinity of phagocytic cups are scarce or absent $[178,182]$ but f-actin and associated proteins such as paxillin and talin can be found clustered around the parasite engulfment regions. These findings are in agreement with recent observations by Kima et al. [161] that $L$. (L.) amazonensis amastigote entry is mediated by $\mathrm{Fc} \gamma \mathrm{R}$ in vivo. Amastigote internalization involves classical receptormediated pagocytosis but the following signaling events involving phosphotyrosine-containing proteins are subverted by the parasite. This may promote intracellular parasite survival and proliferation.

Cross-linking of $\mathrm{CD} 8 \alpha$ - and $\beta$-chains in macrophages stimulates NO production via Src family of PTKs and killing of L. (L.) major [141]. Likewise, treatment of infected macrophages with the broad-specificity PTK inhibitor increases parasite burden, a fact correlated to abrogation of $\mathrm{NO}$ release by these cells [183].

The mechanisms underlying genetic control of leishmanial infection by nramp also involve MAP kinase signaling [333]. Expression of NRAMP protein in response to LPS, inflammatory cytokines (e.g. IFN- $\gamma$, IL- $1 \beta$, TNF- $\alpha$ ) or infectious agents is upregulated intracellularly by at least two MAP kinase components, p38 and p42/p44 ERK. It was recently shown [109] that synthetic leishmanial LPG stimulates ERK, leading to suppression of IL-12(p40). Conflicting results were reported neverthless. Living $L$. ( $L$.) donovani promastigotes were shown to activate ERK1/2 and p38 MAPK in IFN- $\gamma$-primed but not in naive bone marrow macrophages [239]. Also, LPG-deficient mutants induced significantly higher levels of ERK $1 / 2$ phosphorylation; clearly demonstrating that results obtained using synthetic and/or purified parasite-derived molecules must be carefully interpreted and may not reflect the entire in vivo situation. It should be stressed out that p42/p44 ERK activation may be blocked by TGF- $\beta 1$. These facts may be relevant to the prime infection by promastigotes, impacting in the outcome of disease by preventing the generation of a protective Th1 response. Another mechanism of ERK dephosphorylation involves increased ceramide synthesis. The ceramideinduced downregulation of ERK is also associated to inhibition of the pleiotropic transcription factor activated protein 1 (AP-1) and NF-кB [119].

The recent findings concerning inhibition of NF- $\mathrm{KB}$ activation by impaired degradation of the I $\mathrm{B}$ regulatory protein [239] may reinforce the associated suppression of TNF- $\alpha$ $[56,247]$, a pro-inflammatory cytokine involved in nonspecific early immune and Th1-driven responses. Interestingly, NF- $\mathrm{B}$ is involved in transcription of IL-12(p40), which is also defective in Leishmania-infected cells [reviewed in 43, 189]. Indeed, NF- $\kappa$ B2 knockout mice are susceptible to $L$. (L.) major infection due to impairment of CD40-CD40L engagement resulting in IL-12 deficiency [292].

Leishmania parasites also fail to activate the phosphorylation of p54/p46 c-Jun N-terminal kinase [JNK, 72]. This class of MAP kinase is usually associated to stress responses and plays an important role in the regulation of Th differentiation. The impairment of JNK may regulate Th1-Th2 responses in leishmaniasis. Jnkl-deficient mice are unable to resolve $L$. (L.) major infection due to the generation of simultaneous Th1 and Th2 immunity [72]. Th2-derived cytokines have been shown to abrogate macrophage activation, rendering genetically resistant into susceptible mice.

Another gene associated to leishmaniasis is the $S c l-2$. It was identified in DBA/2 mice infected with $L$. (L.) mexicana [254] and controls severity of disease phenotype. It was mapped on mouse chromossome 4 and human $9 \mathrm{p}$ and may provide important parallels to the evidence that a proportion of people who become infected with Leishmania but remain asymptomatic. Unfortunately little was done since its identification and one can only guess JAK kinase as a possible candidate by location [38].

\section{SIGNAL TRANSDUCTION AS TARGET FOR CHEMOTHERAPY INTERVENTION}

The knowledge about signal transduction pathways altered by Leishmania parasites can be used to generate new potential drugs targeting specific parasite molecules involved in macrophage dysfuntions. In this regard the use of vanadium derivatives such as $\mathrm{bpV}(\mathrm{phen})$ and $\mathrm{mpV}(\mathrm{pic})$ has yielded encouraging results in the control of murine leishmaniasis progression [184, 223]. These drugs are insulin-mimetic agents and potent inhibitors of PTPases. The mechanisms of action of these compounds remain to be determined. It was suggested that vanadium derivatives induce rapid increases in iNOS mRNA in the liver of Leishmania-infected mice [184], neverthless discrepant results were obtained in other animal models. PTPase inhibitors such as pervanadate and phenylarsine oxide (PAO) significantly reduced $i N O S$ transcription by blockage of cytokine-induced NF- $\kappa \mathrm{B}$ activation in rat hepatocytes [305]. Besides preventing dephosphorylation of key macrophage 
molecules, these compounds may exert effects in the regulation of parasite growth since PTPase activity was previously detected in L. (L.) donovani [73]. Other PTPase inhibitors such as zinc sulphate [169] were also successfully tested in vitro and in vivo murine models of Old and New World cutaneous leishmaniasis [212].

Recent studies conducted by Pathak and Yi [229] demonstrated that the antimoniate sodium stibogluconate (Pentostam), the drug of choice for leishmaniasis treatment during the last 5 decades $[33,257]$, is a potent inhibitor of tyrosine phosphatases especially SHP-1, SHP-2 and PTP1-B. These findings may be of great relevance since the pharmacological mechanism of pentostam is poorly understood. It is accepted that antimonials act by inhibiting parasite glycolytic enzymes [33] but efficacy in humans is dependent upon a functional Th1 response [211]. The fact that pentostam targets macrophage SHP-1 is consistent with previous observations that vanadium compounds control Leishmania progression in susceptible mice [223].

Another potential target for chemotherapy intervention may be the macrophage MAP kinase cascade. The parasiteinduced increase in SHP-1 activity leads to dephosphorylation of major components of this pathway, which is downstream for numerous signaling networks. SB203580, a specific inhibitor of p38MAPK, increases $L$. (L.) donovani survival in human peripheral blood mononuclear cells whereas anysomycin (p38MAPK and JNK agonist) reduces it [152]. Administration of anysomycin in $L$. (L.) major-infected $\mathrm{Balb} / \mathrm{c}$ mice results in significant reduction in the parasite burden and establishement of a Th1-driven response. Anysomycin-primed mice infected with a low dose of $L$. $(L$.) major also developed significantly less severe disease during re-infection [12]. The mechanism of action proposed by these authors relies on rescue of macrophage function and further $\mathrm{T}$ cell activation after CD40-CD40L engagement, which is impaired in infected macrophages [12].

Splenic and peripheral blood mononuclear cells from golden hamsters presenting progressive VL exhibit gradual impairment of proliferative responses which are mediated by both PKC and MAPK. Restoration of PKC activity can be achieved with Ser/Thr phosphatase inhibitor okadaic acid (OA) or an anti-transforming growth factor $\beta$ (anti-TGF- $\beta$ ) neutralizing antibody [197], which is also elevated in VL [126].

Other authors have proposed developing antileishmanial candidates targeted to parasite signaling networks. The presence of PKC in Leishmania has never been shown but a PKC-like activity sensitive to phorbol esters and staurosporine was demonstrated $[25,41,314,316]$ as well as it possible role in infection [314]. A new class of PKC inhibitors (imidazolidinone compounds) was shown to present great activity against amastigotes in comparison with the antimoniate glucantime. Parasite burden in liver and spleen were reduced with imidazolidinone administration, suggesting that parasite PKC may also constitute a putative therapeutic target [8].

Intensive studies using different animal models should be tested in order to confirm the efficacy and possible therapeutical use of these compounds in human beings, some of them already tested in clinical trials such as vanadium derivatives for the treatment of diabetes mellitus [125]. It clearly demonstrates a potential to the generation of safer therapies for leishmaniasis based on signal trasduction regulation.

\section{ACKNOWLEDGEMENTS}

We thank Mrs. Elisângela Sodré for secretarial assistance. Work at the authors' laboratory was supported by grants from Fundação de Amparo à Pesquisa do Estado da Bahia (FAPESB), Conselho Nacional de Desenvolvimento Científico e Tecnológico (CNPq), Coordenação de Aperfeiçoamento de Pessoal de Nível Superior (CAPES PROCAD) and Fundação Oswaldo Cruz (FIOCRUZ).

\section{ABBREVIATIONS}

\begin{tabular}{|c|c|c|}
\hline AcP & $=$ & Acid phosphatase \\
\hline AP-1 & $=$ & Activated protein 1 transcription factor \\
\hline PPG & $=$ & Amastigote proteophosphoglycan \\
\hline $\mathrm{CR}$ & $=$ & Complement receptor \\
\hline CRP & $=$ & Acute phase C-reative protein \\
\hline DAG & $=$ & Diacylglicerol \\
\hline DCL & $=$ & Diffuse cutaneous leishmaniasis \\
\hline $\mathrm{ECM}$ & $=$ & Extracellular matrix \\
\hline $\mathrm{EF}$ & $=$ & Elongation factor \\
\hline ER & $=$ & Endoplasmic reticulum \\
\hline ERK & $=$ & Extracellular-regulated protein kinase \\
\hline FAK & $=$ & Focal adhesion kinase \\
\hline FcR & $=$ & $\begin{array}{l}\text { Receptor for the Fc portion of } \\
\text { immunoglobulins }\end{array}$ \\
\hline FN & $=$ & Fibronectin \\
\hline $\mathrm{FP}$ & $=$ & Flagellar pocket \\
\hline $\mathrm{fPPG}$ & $=$ & Filamentous proteophosphoglycan \\
\hline GIPL & $=$ & Glycoinositolphospholipid \\
\hline gp63 & $=$ & Glycoprotein 63 \\
\hline GPI & $=$ & Glycosylphosphatidylinositol \\
\hline HETE & $=$ & Hydroxyeicosatetraenoic acid \\
\hline ICAM & $=$ & Intercellular adhesion molecule \\
\hline IFN & $=$ & Interferon \\
\hline $\operatorname{Ig}$ & $=$ & Immunoglobulin \\
\hline iNOS & $=$ & Inducible nitric oxide synthase \\
\hline IP-10 & $=$ & IFN- $\gamma$ inducible protein 10 \\
\hline JAK & $=$ & Janus kinase \\
\hline KMP-11 & $=$ & Kinetoplastid membrane protein 11 \\
\hline LAMP & $=$ & Lysosome-associated membrane protein \\
\hline LBP & $=$ & Laminin binding protein \\
\hline LMPK & $=$ & Leishmania homologue to MAP kinase \\
\hline $\mathrm{LN}$ & $=$ & Laminin \\
\hline
\end{tabular}




\begin{tabular}{|c|c|c|}
\hline LPG & $=$ & Lipophosphoglycan \\
\hline LPK & $=$ & Leishmania ecto-protein kinase \\
\hline LPS & $=$ & Lipopolisaccharide \\
\hline MAPK & $=$ & Mitogen-activated protein kinase \\
\hline MARCKS & $=$ & Myristoylated alanine-rich $\mathrm{C}$ kinase \\
\hline MDR & $=$ & Multidrug resistance \\
\hline MFR & $=$ & Mannose-fucose receptor \\
\hline MHC & $=$ & Major histocompatibility complex \\
\hline MIP & $=$ & Macrophage inflammatory protein \\
\hline MRP & $=$ & MARCKS-related protein \\
\hline MVT & $=$ & Multivesicular tubule \\
\hline NF-kB & $=$ & Nuclear factor $\mathrm{kB}$ \\
\hline NRAMP & $=$ & $\begin{array}{l}\text { Natural resistance-associated macrophage } \\
\text { protein }\end{array}$ \\
\hline ODC & $=$ & Ornithine decarboxylase \\
\hline ORF & $=$ & Open reading frame \\
\hline PAO & $=$ & Phenylarsine oxide \\
\hline PCD & $=$ & Programmed cell death \\
\hline PGE & $=$ & Prostaglandin E \\
\hline PI & $=$ & Phosphatidylinositol \\
\hline PKA & $=$ & $\begin{array}{l}\text { Protein Kinase A (cAMP-dependent protein } \\
\text { kinase) }\end{array}$ \\
\hline PKC & $=$ & Protein kinase $\mathrm{C}$ \\
\hline PLC & $=$ & Phospholipase C \\
\hline PMA & $=$ & Phorbol myristate acetate \\
\hline PMN & $=$ & Polymorphonuclear leukocytes \\
\hline PPase & $=$ & Protein phosphatase \\
\hline PPG & $=$ & Proteophosphoglycan \\
\hline PS & $=$ & Phosphatidylserine \\
\hline PSP & $=$ & Promastigote surface protease (gp63) \\
\hline PTK & $=$ & Protein tyrosine kinase \\
\hline PTP & $=$ & Protein tyrosine phosphatase \\
\hline PV & $=$ & Parasitophorous vacuole \\
\hline RNI & $=$ & Reactive nitrogen intermediates \\
\hline ROI & $=$ & Reactive oxygen intermediates \\
\hline SAP & $=$ & Secreted acid phosphatase \\
\hline SHP-1 & $=$ & Src homology protein phosphatase 1 \\
\hline SOCS3 & $=$ & Supressor of cytokine signaling 3 \\
\hline SOD & $=$ & Superoxide dismutase \\
\hline STAT & $=$ & Signal transducer and activator of transcipion \\
\hline TGF & $=$ & Transforming growth factor \\
\hline TNF & $=$ & Tumor necrosis factor \\
\hline VL & $=$ & Visceral leishmaniasis \\
\hline
\end{tabular}

\section{REFERENCES}

[1] Aebischer, T.; Harbecke, D.; Ilg, T. Infect. Immun., 1999, 67, 5379.

[2] Aga, E.; Katschinski, D.M.; van Zandbergen, G.; Laufs, H.; Hansen, B.; Muller, K.; Solbach, W.; Laskay, T. J. Immunol., 2002,169, 898 .

[3] Akiyama, T.; Ogawara, H. Methods Enzymol., 1991, 201, 362

[4] Alexander, J. Trans. Roy. Soc. Trop. Med. Hyg., 1978, 72, 645.

[5] Alexander, J.; Coombs, G.H.; Mottran, J.C. J. Immunol., 1998, 161, 6794.

[6] Allen, L.; Aderem, A. EMBO J., 1995, 14, 1109

[7] Alvar, J. Parasitol. Today, 1994, 10, 160.

[8] Alvarez, N.; Robledo, S.; Velez, I.D.; Robert, J.M.; Le Baut, G.; Le Pape, P. J. Enzyme Inhib. Med. Chem., 2002, 17, 443.

[9] Antoine, J.C.; Lang, T.; Prina, E.; Courret, N.; Hellio, R. J. Cell Sci., 1999, 112, 2559.

[10] Antoine, J.C.; Prina, E.; Lang, T.; Courret, N. Trends Microbiol. 1998, 6, 392.

[11] Augusto, O.; Linhares, E.; Giorgio, S. Braz. J. Med. Biol. Res., 1996, 29, 853 .

[12] Awasthi, A.; Mathur, R.; Khan, A.; Joshi, B.N.; Jain, N.; Sawant, S.; Boppana, R.; Mitra, D.; Saha, B. J. Exp. Med., 2003,197, 1037.

[13] Bacchi, C.J.; Nathan, H.C.; Hutner, S.H.; McCann, P.P.; Sjoerdsma, A. Science, 1980, 210, 332.

[14] Bacchi, C.J.; Sanabria, K.; Spiess, A.J.; Vargas, M.; Marasco, C.J. Jr; Jimenez, L.M.; Goldberg, B.; Sufrin, J.R. Antimicrob. Agents Chemother., 1997, 41, 2108.

[15] Balaña-Fouce, R.; Reguera, R.M.; Cubria, J.C.; Ordóñez, D. Gen. Pharmacol., 1998, 30, 435.

[16] Bandyopadhyay, K.; Karmakar, S.; Biswas, A.; Das, P.K. Eur. J. Biochem., 2003, 270, 3806.

[17] Bandyopadhyay, K.; Karmakar, S.; Ghosh, A.; Das, P.K. Eur. J. Biochem., 2002, 269, 1622.

[18] Barbieri, C.L.; Brown, K; Rabinovitch, M. Z. Parasitenkd., 1985, 71, 159.

[19] Barbieri, C.L.; Doine, A.I.; Freymuller, E. Exp. Parasitol., 1990 71, 218.

[20] Barral-Netto, M.; Barral, A.; Brownell, C.E.; Skeiky, Y.A.W.; Ellingsworth, L.R.; Twardzik, D.R.; Reed, S.G. Science, 1992, 257, 545.

[21] Bastien, P.; Blaineau, C.; Pagès, M. Parasitol. Today, 1992, 8, 174.

[22] Basu, N.; Sett, R.; Das, P.K. Biochem. J., 1991, 277, 451.

[23] Bates, P.A. Parasitol. Today, 1995, 11, 317.

[24] Bates, P.A.; Robertson, C.D.; Tetley, L.; Coombs, G.H. Parasitol., 1992, 105, 193.

[25] Becker, S.; Jaffe, C.L. Parasitol. Res., 1997, 83, 273

[26] Belkaid, Y.; Kamhawi, S.; Modi, G.; Valenzuela, J.; Noben-Trauth, N.; Rowton, E.; Ribeiro, J.; Sacks, D.L. J. Exp. Med., 1998, 188 , 1941.

[27] Bell, R.M. Cell, 1986, 45, 631.

[28] Bellamy, R. Microb. Infect., 1999, 1, 23.

[29] Benchimol, M.; De Souza, W. Z. Parasitenkd., 1981, 66, 25.

[30] Benne, R. Trends Genet., 1990, 6, 177.

[31] Bente, M.; Harder, S.; Wiesgigl, M.; Heukeshoven, J.; Gelhaus, C.; Krause, E.; Clos, J.; Bruchhaus, I. Proteomics, 2003, 3, 1811.

[32] Berenguer, J.; Gomez-Camdera, F.; Padilla, B.; Rodriguez-Ferrero, M.; Anaya, F.; Moreno, S.; Valderrabano, F. Transplantation, 1998, 65, 1401.

[33] Berman, J. Curr. Opin. Infect. Dis., 2003, 16, 397.

[34] Bertholet, S.; Dickensheets, H.L.; Sheikh, F.; Gam, A.A.; Donnelly, R.P.; Kenney, R.T. Infect. Immun., 2003, 71, 2095.

[35] Beverley, S.M.; Turco, S.J. Trends Microbiol., 1998, 6, 35.

[36] Bhattachryya, S.; Ghosh, S.; Jhonson, PL; Bhattacharya, S.K.; Majumdar, S. Infect. Immun., 2001, 69, 1499.

[37] Bhunia, A.K.; Sarkar, D.; Das, P.K. J. Euk. Microbiol., 1996, 43, 373.

[38] Blackwell, J.M. Parasitol., 1996, 112, 567.

[39] Blanchette, J.; Racette, N.; Faure, R.; Siminovitch, K.A.; Olivier, M. Eur. J. Immunol., 1999, 29, 3737.

[40] Bliska, J.B.; Guan, K.; Dixon, J.E.; Falkow, S. Proc. Natl. Acad. Sci. USA, 1991, 88,1187 .

[41] Blum, J.J. J. Euk. Microbiol., 1994, 41, 1.

[42] Blum, B.; Bakalara, N.; Simpson, L. Cell, 1990, 60, 189.

[43] Bodgan, C.; Gessner, A.; Solbach, W.; Röllinghoff, M. Curr. Opin. Immunol., 1996, 8, 517.

[44] Bordier, C. Parasitol. Today, 1987, 3, 151 
[45] Borges, V.M.; Vannier-Santos, M.A.; De Souza, W. Parasitol. Res., 1998, 84, 811.

[46] Boutard, V.; Havouis, R.; Fouqueray, B.; Philippe, C.; Moulinoux, J.P.; Baud, L. J. Immunol., 1995, 155, 2077.

[47] Bouvier, J. Etges, R.J.; Bordier, C. J. Biol. Chem., 1985, 260, 15504.

[48] Brittingham, A.; Chen, G.; McGwire, B.S.; Chang, K.P.; Mosser, D.M. Infect. Immun., 1999, 67, 4477.

[49] Brittingham, A.; Morrison, C.J.; McMaster, W.R.; McGwire, B.S.; Chang, K.P.; Mosser, D.M. J. Immunol., 1995, 155, 3102

[50] Butcher, B.A.; Sklar, L.A.; Seamer, L.C.; Glew, R.H. J. Immunol., 1992, 148, 2879.

[51] Buchmüller-Rouiller, Y.; Betz-Corradin, S.; Maüel, J. J. Immunol., 1992, 148, 1171

[52] Buchmüller-Rouiller, Y.; Maüel, J. J. Immunol., 1986, 136, 3884

[53] Buchmüller-Rouiller, Y.; Maüel, J. J. Immunol., 1991, 146, 217.

[54] Campo-Aasen, I.; Aleman, C.; Convit, J. Trans. Roy. Soc. Trop. Med. Hyg., 1973, 67, 122.

[55] Camus, D.; Zalis, M.G.; Vannier-Santos, M.A.; Banic, D.M. Bras. J. Med. Biol. Res., 1995, 28, 399.

[56] Carrera, L.; Gazzinelli, R.T.; Badolato, R.; Hieny, S.; Muller, W.; Kuhn, R.; Sacks, D.L. J. Exp. Med., 1996, 183, 515.

[57] Cassatella, M.A.; Gasperini, S.; Calzetti, F.; Bertagnin, A.; Luster, A.D.; McDonald, P.P. Eur. J. Immunol., 1997, 27, 111

[58] Chakour, R.; Guler, R.; Bugnon, M.; Allenbach, C.; Garcia, I.; Mauel, J.; Louis, J.; Tacchini-Cottier, F. Infect. Immun ., 2003, 71, 5287.

[59] Chakraborty, R.; Chakraborty, P.; Basu, M.K. Biosci. Rep., 1998 18, 129.

[60] Chakraborty, P.; Das, P.K. Mol. Biochem. Parasitol., 1988, 28, 55.

[61] Chang, K.P. Am. J. Trop. Med. Hyg., 1981, 30, 334.

[62] Chang, K.P. Int. Rev. Cytol., 1983, 14, 267.

[63] Channon, J.Y.; Roberts, M.B.; Blackwell, J.M. Immunol., 1984, 53, 345.

[64] Chaudhuri, G.; Chang, K.P. Mol. Biochem. Parasitol., 1988, 27, 43.

[65] Chen, D.Q.; Kolli, B.K.; Yadava, N.; Lu, H.G.; Gilman-Sachs, QA.; Peterson, D.A.; Chang, K.P. Infect. Immun., 2000, 68, 80.

[66] Chiang, S.C.; Ali, V.; Huang, A.L.; Chu, K.Y.; Lee, S.T. Mol. Biochem. Parasitol., 2001, 112, 263.

[67] Chow, C.W.; Grinstein, S.; Rotstein, O.D. New Horizons, 1995, 3 , 342 .

[68] Clayton, C.; Hausler, T.; Blattner, J. Microbiol. Rev., 1995, 59,

[69] Cobb, M.H.; Goldsmith, E.J. J. Biol. Chem., 1995, 270, 14843.

[70] Collins, M.G.; Hourani, S.M. Trends Pharmacol. Sci., 1993, 14, 360.

[71] Conceicao-Silva, F.; Hahne, M.; Schroter, M.; Louis, J.; Tschopp, J. Eur. J. Immunol., 1998, 28, 237.

[72] Constant, S.L.; Dong, C.; Yang, D.D.; Wysk, M.; Davis, R.J.; Flavell, R.A. J. Immunol., 2000,165, 2671.

[73] Cool, D.E.; Blum, J.J. Mol. Cell. Biochem., 1993, 127/128, 143

[74] Corradin, S.; Maüel, J.; Ransijn, A.; Stürzinger, C.; Vergères, G. J. Biol. Chem., 1999, 274, 16782.

[75] Corradin, S.; Ransijn, A.; Corradin, G.; Roggero, M.A.; Schmitz, A.A.; Schneider, P.; Maüel, J.; Vergères, G. J. Biol. Chem., 1999, 274, 25411.

[76] Courret, N.; Frehel, C.; Gouhier, N.; Pouchelet, M.; Prina, E.; Roux, P.; Antoine, J.C. J. Cell Sci., 2002, 115, 2303.

[77] Culley, F.J.; Harris, R.A.; Kaye, P.M.; McAdam, K.P.; Raynes, J.G. J. Immunol., 1996, 156, 4691.

[78] Das, S.; Saha, A.K.; Mukhopadhyay, N.K.; Glew, R.H. Biochem. J., 1986, 240, 641.

[79] Das, S.; Saha, A.K.; Remaley, A.T.; Glew, R.H.; Dowing, J.N.; Kajiyoshi, M.; Gottlieb, M. Mol. Biochem. Parasitol., 1986, 20, 143.

[80] Das, G.; Vohra, H.; Rao, K.; Saha, B.; Mishra, G.C. Scand. J. Immunol., 1999, 49, 307.

[81] Da Silva, R.P.; Hall, B.F.; Joiner, K.A.; Sacks, D.L. J. Immunol., 1989, $143,617$.

[82] Davis, C.R.; Cooper, A.M.; Peacock, C.; Lane, R.P.; Blackwell, J.M. Parasitol., 1991, 101, 337.

[83] Debrabant, A.; Lee, N.; Bertholet, S.; Duncan, R.; Nakhasi, H.L. Int. J. Parasitol., 2003, 33, 257.

[84] Delvig, A.A.; Robinson, J.H. Eur. J. Immunol., 1999, 29, 2414.
[85] Dermine, J.F.; Scianimanico, S.; Prive, C.; Descoteaux, A.; Desjardins, M. Cell. Microbiol., 2000, 2, 115.

[86] Descoteux, A.; Matlashewski, G. Mol. Cell. Biol., 1989, 9, 5223.

[87] Descoteaux, A.; Matlashewski, G.; Turco, S.J. J. Immunol., 1992, 149, 3008.

[88] Descoteaux, A.; Turco, S.J. Parasitol. Today, 1993, 9, 468

[89] Descoteaux, A.; Turco, S.J.; Sacks, D.L.; Matlashewski, G. J. Immunol., 1991, 146, 2747.

[90] Desjardins, M.; Descoteaux, A. J. Exp. Med., 1997, 185, 2061.

[91] Desjeux, P. Wld. Hlth. Statist. Quart., 1992, 45, 267.

[92] Desjeux, P. In Leishmania and HIV in gridlock. WHO/UNAIDS, 1998.

[93] De Souza, W. Mem. Inst. Oswaldo Cruz, 1988, 83, 546.

[94] De Souza, W. Parasitol. Res., 2002, 88, 1013.

[95] Dey, R.; Mitra, S.; Datta, S.C. J. Parasitol., 1995, 81, 683.

[96] Dillon, R.J.; Lane, R.P. Parasitol., 1999, 118, 27.

[97] Docampo, R.; Moreno, S.N. Parasitol. Today, 1999, 15, 433.

[98] Domínguez, M.; Toraño, A. J. Exp. Med., 1999, 189, 25.

[99] Dominguez, M.; Moreno, I.; Aizpurua, C.; Toraño, A. Microb. Infect., 2003, 5, 507.

[100] Duboise, S.M.; Vannier-Santos, M.A.; Costa-Pinto, D.; Rivas, L.; Pan, A.A.; Traub-Cseko, Y.; De Souza, W.; McMahon-Pratt, D. Mol. Biochem. Parasitol., 1994, 68, 119.

[101] Duclos, S.; Corsini, R.; Desjardins, M. J. Cell Sci., 2003, 116, 907.

[102] Dumas, C.; Ouellette, M.; Tovar, J.; Cunningham, M.L.; Fairlamb, A.H.; Tamar, S.; Olivier, M.; Papadopoulou, B. EMBO J., 1997, 16,2590 .

[103] Dutta, M.; Bandyopadhyay, R.; Basu, M.K. Parasitol., 1994, 109, 139.

[104] Eidsmo, L.; Wolday, D.; Berhe, N.; Sabri, F.; Satti, I.; El Hassan, A.M.; Sundar, S.; Chiodi, F.; Akuffo,H. Clin. Exp. Immunol., 2002, $130,307$.

[105] Eilan, Y.; El-On, J.; Spira, D. Exp. Parasitol., 1985, 59, 161.

[106] Elhay, M.; Kelleher, M.; Bacic, A.; McConville, M.J.; Tolson, D.L.; Pearson, T.W.; Handman, E. Mol. Biochem. Parasitol., 1990, $40,255$.

[107] Ellis, S.L.; Shakarian, A.M.; Dwyer, D.M. Exp. Parasitol., 1998, $89,161$.

[108] Eltoum, I.A.; Zijlstra, E.E.; Ali, M.S.; Ghalib, H.W.; Satti, M.M.; Eltoum, B.; el-Hassan, A.M. Am. J. Trop. Med. Hyg., 1992, 46, 57.

[109] Estevez, A.M.; Simpson, L. Gene, 1999, 240, 247. antes 112.

[110] Farrell, J.P.; Kirkpatrick, C.E. J. Immunol., 1987, 138, 902.

[111] Feng, G.J.; Goodridge, H.S.; Harnett, M.M.; Wei, X.Q.; Nikolaev, A.V.; Higson, A.P.; Liew, F.Y. J. Immunol., 1999, 163, 6403.

[112] Ferreira, C.S.; Martins, P.S.; Demicheli, C.; Brochu, C.; Ouellette, M.; Frezard, F. Biometals, 2003, 16, 441.

[113] Formica, S.; Roach, T.I.; Blackwell, J.M. Immunol., 1994, 82, 42.

[114] Frame, M.J.; Mottran, J.C.; Coombs, G.H. Parasitol., 2000, 121 367.

[115] Freire-de-Lima, C.G.; Nascimento, D.O.; Soares, M.B.; Bozza P.T.; Castro-Faria-Neto, H.C.; Mello, F.G.; DosReis, G.A.; Lopes, M.F. Nature, 2000 403, 199.

[116] Freitas-Balanco, J.M.; Moreira, M.E.; Bonomo, A.; Bozza,P.T.; Amarante-Mendes, G.; Pirmez, C.; Barcinski, M.A. Curr. Biol., 2001, 11, 1870.

[117] Frézard, F.; Demicheli, C.; Ferreira, C.S.; Costa, M.A. Antimicrob. Agents Chemother., 2001, 45, 913.

[118] Gagnon, E.; Duclos, S.; Rondeau, C.; Chevet, E.; Cameron, P.H.; Steele-Mortimer, O.; Paiement, J.; Bergeron, J.J.; Desjardins, M. Cell, 2002, 110, 119.

[119] Ganguly, N.K.; Sodhi, S.; Kaul, N.; Malla, N.; Mahaian, R.C. J. Pharm. Pharmacol., 1991, 43, 140.

[120] Ghosh, A.; Bandyopadhyay, K.; Kole, L.; Das, P.K. Biochem. J., 1999, 337, 551 .

[121] Ghosh, S.; Bhattacharyya, S.; Sirkar, M.; Sa, G.S.; Das, T.;Majumdar, D.; Roy, S.; Majumdar, S. Infect. Immun., 2002, 70, 6828.

[122] Ghosh, A.; Kole, L.; Bandyopadhyay, K.; Sarkar, K.; Das, P.K. Biochem. Biophys. Res. Commun., 1996, 226, 101.

[123] Giorgione, J.R.; Turco, S.J.; Epand, R.M. Proc. Natl. Acad. Sci. USA, 1996, 93, 11634.

[124] Glaser, T.A.; Mukkada, A.J. Mol. Biochem. Parasitol., 1992, 51, 1.

[125] Glaser, T.A.; Utz, G.A.; Mukkada, A.J. Mol. Biochem. Parasitol. 1992, 51,9 .

[126] Glew, R.H.; Saha, A.K; Das, S.; Remaley, A.T. 1988, Microbiol. Rev., 52, 412. 
[127] Goldfine, A.B.; Simonson, D.C.; Folli, F.; Patti, M.E.; Kahn, C.R. Mol. Cell. Biochem., 1995, 153, 217.

[128] Gomes, N.A.; Gatass, C.R.; Barreto-de-Souza, V.; Wilson, M.E.; DosReis, G.A. J. Immunol., 2000, 164, 2001.

[129] Gonzalez-Aseguinolaza, G.; Taladriz, S.; Marquet, A.; Larraga, V. Parasitol. Res., 2000, 86, 36.

[130] Gossage, S.M.; Rogers, M.E.; Bates, P.A. Int. J. Parasitol., 2003, 33,1027 .

[131] Gottesman, M.M ; Pastan, I. Ann. Rev, Biochem, 1993, 62, 385.

[132] Green, S.J.; Nacy, C.A.; Meltzer, M.S. J. Leuk. Biol., 1991, 50, 93.

[133] Greenberg, S.; Silverstein, S.C. In Fundamental Immunology; W.E. Paul, Ed.; Raven Press Ltda: New York, 1993, pp. 941-964.

[134] Gupta, N.; Goyal, N.; Rastogi, A.K. Trends Parasitol., 2001, 17, 150.

[135] Guy, R.A.; Belosevic, M. Infect. Immun., 1993, 61, 1553.

[136] Haimeur, A.; Guimond, C.; Pilote, S.; Mukhopadhyay, R.; Rosen, B.P.; Poulin, R.; Ouellette, M. Mol. Microbiol., 1999, 34, 726.

[137] Hall, L.R.; Titus, R.G. J. Immunol. 1995, 155, 3501.

[138] Henriques, C.; De Souza, W. Parasitol. Res., 2000, 86, 215.

[139] Herman, R. Infect. Immun., 1980, 28, 585.

[140] Hermoso, T.; Fishelson, Z.; Becker, S.I.; Hirschberg, K.; Jaffe, C.L. EMBO J., 1991, 10, 4061.

[141] Higuchi, Y.; Setoguchi, M.; Yoshida, S.; Akizuki, S.; Yamamoto, S. Oncogene, 1988, 2, 515 .

[142] Hilley, J.D.; Zawadzki, J.L.; McConville, M.J.; Coombs, G.H.; Mottran, J.C. Mol. Biol. Cell, 2000, 11, 1183.

[143] Hirji, N.; Lin, T.J.; Bissonnette, E.; Belosvic, M.; Befus, A.D. J. Immunol., 1998, 160, 6004.

[144] Hodgkinson, V.H.; Soong, L.; Duboise, S.M.; McMahon-Pratt, D. Exp. Parasitol., 1996, 83, 94.

[145] Hörmann, H.; Jelinic, V.; Richter, H. Biol. Chem. Hoppe-Seyler, 1989, 370, 691 .

[146] Ilg, T. EMBO J., 2000, 19, 1953.

[147] Ilg, T.; Demar, M.; Harbecke, D. J. Biol. Chem., 2000, 276, 4988.

[148] Ilg, T.; Handman, E.; Stierhof, Y.D. Biochem. Soc. Trans., 1999, 27,518 .

[149] Ilgoutz, S.C.; Mullin, K.A.; Southwell, B.R.; McConville, M.J. EMBO J., 1999, 18, 3643.

[150] Iniesta, V.; Gómez-Nieto, L.C.; Corraliza, I. J. Exp. Med., 2001, 193, 777.

[151] Jardim, A.; Tolson, D.L.; Turco, S.J.; Pearson, T.W.; Olafson, R.W. J. Immunol., 1991, 147, 3538.

[152] Jensen, B.S.; Odum, N.; Jorgensen, N.K.; Christophersen, P.; Olesen, S.P. Proc. Natl. Acad. Sci. USA, 1999, 96, 10917.

[153] Jiao, H.; Berrada, K.; Yang, W.; Tabrizi, M.; Platanias, L.C.; Yi, T. Mol. Cell. Biol., 1996, 16, 6985.

[154] Junghae, M.; Raynes, J.G. Infect. Immun., 2002, 70, 5026.

[155] Kamhawi, S.; Belkaid, Y.; Modi, G.; Rowton, E.; Sacks, D. Science, 2000, 290, 1351.

[156] Kanashiro, C.A.; Khalil, R.A. Clin. Exp. Pharmacol. Physiol., 1998, 25, 974.

[157] Kane, M.M.; Mosser, D.M. Curr. Opin. Hematol., 2000, 7, 26.

[158] Kane, M.M.; Mosser, D.M. J. Immunol., 2001, 166, 1141.

[159] Kapoor, P.; Ghosh, A.; Madhubala, R. FEMS Microbiol. Lett., 1999, 176, 437.

[160] Katakura, K.; Kobayashi, A. Infect. Immun., 1988, 56, 2856.

[161] Katz, O.; Waitumbi, J.N.; Zer, R.; Warburg, A. Am. J. Trop. Med. Hyg., 2000, 62, 145.

[162] Kelleher, M.; Moody, S.F.; Mirabile, P.; Osborn, A.H.; Bacic, A.; Handman, E. Infect. Immun., 1995, 63, 43.

[163] Kima, P.E.; Constant, S.L.; Hannum, L.; Colmenares, M.; Lee, K.S.; Haberman, A.M.; Shlomchik, M.J.; McMahon-Pratt, D. J. Exp. Med., 2000, 191, 1063.

[164] Klee, C.B.; Ren, H.; Wang, X. J. Biol. Chem., 1998, 273, 13367.

[165] Kock, N.P.; Gabius, H.J.; Schmitz, J.; Schottelius, J. Trop. Med. Int. Health, 1997, 2, 863 .

[166] Kubar, J.; Quaranta, J.F.; Aufeuvre, J.P.; Marty, P.; Lelièvre, A.; Le Fichoux, Y. Nat. Med., 1997, 3, 368.

[167] Kukita, M.; Hirata, M.; Koga, T. Biochim. Biophys. Acta, 1986, $885,121$.

[168] Langford, C.K.; Ewbank, A.S.; Hanson, S.S.; Ullman, B.; Landfear, S.M. Mol. Biochem. Parasitol., 1992, 55, 51.

[169] Laskay, T.; van Zandbergen, G.; Solbach, W. Trends Microbiol., 2003, 11, 210.

[170] Lau, K.H.W.; Farley, J.R.; Baylink, D.J. Biochem. J., 1989, 257, 23.
[171] Laufs, H.; Muller, K.; Fleischer, J.; Reiling, N.; Jahnke, N.; Jensenius, J.C.; Solbach, W.; Laskay, T. Infect. Immun., 2002, 70, 826.

[172] Lee, Y.J.; Panek, R.B.; Huston, M.; Benveniste, E.N. Am. J. Physiol., 1995, 268, C127.

[173] Linares, E.; Giorgio, S.; Mortara, R.A.; Santos, C.X.; Yamada, A.T.; Augusto, O. Free Radic. Biol. Med., 2001, 30, 1234.

[174] Li, J.; Hunter, C.A.; Farrel, J.P. J. Immunol., 1999, 162, 974.

[175] Li, J.; Zhu, Z.; Bao, Z. J. Biol. Chem., 1996, 271, 12985.

[176] Liu, X.; Chang, K.P. Proc. Natl. Acad. Sci. USA, 1992, 89, 4991.

[177] Lira, R.; Rosales-Encina, J.; Argüello, C. Exp. Parasitol., 1997, 85, 149.

[178] Love, D.C.; Esko, J.D.; Mosser, D.M. J. Cell Biol., 1993, 123, 759.

[179] Love, D.C.; Kane, M.M.; Mosser, D.M. Exp. Parasitol., 1998, 88 , 161.

[180] Luz, K.G.; da Silva, V.O.; Gomes, E.M.; Machado, F.C.; Araujo, M.A.; Fonseca, H.E.; Freire, T.C.; d'Almeida, J.B.; Palatinik, M.; Palatinik-de-Souza, C.B. Am. J. Trop. Med. Hyg., 1997, 57, 168.

[181] Lymar, S.; Jiang, Q.; Hurst, J. K. Biochemistry, 1996, 35, 7855.

[182] Martins, A. R.; Dias, M. M.; Vasconcelos, T. M.; Caldo, H.; Tien, M.; Berlett, B. S.; Levine, R. L.; Chock, P. B.; Stadtman, E. R. Proc. Natl. Acad. Sci. USA, 1996, 96, 7809.

[183] Martiny, A.; Meyer-Fernandes, J.R; De Souza, W.; Vannier-Santos, M.A. Mol. Biochem. Parasitol., 1999, 102, 1.

[184] Martiny, A.; Vannier-Santos, M.A.; Borges, V.M.; MeyerFernandes, J.R.; Assreuy, J.; Cunha-e-Silva, N.L.; De Souza, W. Eur. J. Cell Biol., 1996, 71, 206.

[185] Matte, C.; Marquis, J.F.; Blanchette, J.; Gros, P.; Faure, R.; Posner, B.I.; Olivier, M. Eur. J. Immunol., 2000, 30, 2555.

[186] Mbow, M.L.; Bleyenberg, J.A.; Hall, L.R.; Titus, R.G. J. Immunol., 1998, 161, 5571 .

[187] McCann, P.P.; Bacchi, C.J.; Clarkson, A.B. Jr.; Bey, P.; Sjoerdsma, A.; Schecter, P.J.; Walzer, P.D.; Barlow, J.L. Am. J. Trop. Med. Hyg., 1986, 35, 1153 .

[188] McConville, M.J.; Blackwell, J.M. J. Biol. Chem., 1991, 266, 15170.

[189] McDowell, M.A.; Sacks, D.L. Curr. Opin. Microbiol., 1999, 2, 438.

[190] McNeely, T.B.; Rosen, G.; Londner, M.V.; Turco, S.J. Biochem. J., 1989, 259, 601 .

[191] McNeely, T.B.; Turco, S.J. J. Immunol., 1990, 144, 2745.

[192] Miao, L.; Stafford, A.; Nir, S.; Turco, S.J.; Flanagan, T.D.; Epand, R.M. Biochemistry, 1995, 34, 4676.

[193] Michels, P.A.M.; Hannaert, V.; Bringaud, F. Parasitol. Today, 2000, 16, 482 .

[194] Misra, S.; Naskar, K.; Sarkar, D.; Ghosh, D.K. Mol. Cell Biochem., 1991, 102, 13.

[195] Moll, H. Immunol. Today, 1993, 14, 383.

[196] Morehead, J.; Coppens, I.; Andrews, N.W. Infect. Immun., 2002, 70,4571 .

[197] Mookerjee, A.; Sen, P.C.; Ghose, A.C. Infect. Immun., 2003, 71, 2439.

[198] Moore, K.J.; Labrecque, S.; Matlashewski, G. J. Immunol., 1993, $150,4457$.

[199] Moore, K.J.; Matlashewski, G. J. Immunol., 1994, 152, 2930.

[200] Mosser, D.M.; Brittingham, A. Parasitol., 1997, 115, S9.

[201] Mosser, D.M.; Edelson, P.J. J. Immunol., 1985, 135, 2785.

[202] Mosser, D.M.; Edelson, P.J. Nature, 1987, 327, 329.

[203] Mosser, D.M.; Rosenthal, L.A. Semin. Cell. Biol., 1993, 4, 315.

[204] Mosser, D.M.; Springer, T.A.; Dimond, M.S. J. Cell Biol., 1992, 116, 511.

[205] Mosser, D.M.; Vlassara, H.; Edelson, P.J.; Cerami, A. J. Exp. Med., 1987, 165, 140 .

[206] Morales, P.; Torres, J.J.; Salavert, M.; Peman, J.; Lacruz, J.; Sole, A. Transplant. Proc., 2003, 35, 2001.

[207] Mullin, K.A.; Foth, B.J.; Ilgoutz, S.C.; Callaghan, J.M.; Zawadzki, J.M.; McFadden, G.I.; McConville, M.J. Mol. Biol. Cell, 2001, 12, 2364.

[208] Murray, H.W. J. Reticulendothel. Soc., 1982, 31, 479.

[209] Murray, H.W.; Nathan, C.F. J. Exp. Med., 1999, 189, 741

[210] Nabors, G.S.; Farrell, J.P. J. Infect. Dis., 1996, 173, 979.

[211] Najim, R.A.; Sharquie, K.E.; Farjou, I.B. Mem. Inst. Oswaldo Cruz, 1998, 93, 831.

[212] Nandan, D.; Cherkasov, A.; Sabouti, R.; Yi, T.; Reiner, N.E. Biochem. Biophys. Res. Commun., 2003, 302, 646.

[213] Nandan, D.; Lo, R.; Reiner, N.E. Infect. Immun., 1999, 67, 4055.

[214] Nandan, D.; Reiner, N.E. Infect. Immun., 1995, 63, 4495. 
[215] Nicholson, S.E.; De Souza, D.; Fabri, L.J.; Corbin. J.; Willson, T.A.; Zhang, J.G.; Silva, A.; Asimakis, M.; Farley, A.; Nash, A.D.; Metcalf, D.; Hilton, D.J.; Nicola, N.A.; Baca, M. Proc. Natl. Acad. Sci. USA, 2000, 97, 6493.

[216] Noronha, F.S.; Ramalho-Pinto, F.J.; Horta, M.F. Infect. Immun., 1996, 64, 3975.

[217] North, M.J.; Lockwood, B.C. In Biochemistry and Molecular Biology of Parasites, J.J. Marr and M. Müller, Eds., Academic Press, New York, 1995, 67-88.

[218] Olivier, M. Parasitol. Today, 1996, 12, 145

[219] Olivier, M.; Baimbridge, K.G.; Reiner, N.E. J. Immunol., 1992 148,1188

[220] Olivier, M.; Brownsey, R.W.; Reiner, N.E. Proc. Natl. Acad. Sci. USA, 1992, 89, 7481.

[221] Olivier, M.; Cook, P.; Desanctis, J.; Hel, Z.; Wojciechowski, W.; Reiner, N.E.; Skamene, E.; Radzioch, D. Eur. J. Biochem., 1998 251,734 .

[222] Olivier, M.; Romero-Gallo, B.J.; Matte, C.; Blanchette, J.; Posner, B.I.; Tremblay, M.J.; Faure, R. J. Biol. Chem., 1998, 273, 13944.

[223] Opperdoes, F.R.; Michels, P.A. Biochimie., 1993, 75, 231.

[224] O'Sullivan, M.C.; Zhou, Q.; Li, Z.; Durham, T.B.; Rattendi, D.; Lane, S.; Bacchi, C.J. Bioorg. Med. Chem., 1997, 5, 2145.

[225] Palatinik-de-Souza, C.B.; Dutra, H.S.; Borojevic, R. Acta Tropica, 1993, 53, 59 .

[226] Pan, A.A. Exp. Parasitol., 1984, 58, 72

[227] Pan, A.A.; Duboise, S.M.; Eperon, S.; Rivas, L.; Hodgkinson, V.; Traub-Cseko, Y.; McMahon-Pratt, D. J. Euk. Microbiol., 1993, 40, 213.

[228] Pathak, M.K.; Yi, T. J. Immunol., 2001, 167, 3391.

[229] Pearson, R.D.; Steigbigel, R.T. J. Immunol., 1981, 127, 1438.

[230] Perez, E.; Munoz, M.L.; Ortega, A. Exp. Parasitol., 1996, 82, 164.

[231] Peters, C.; Aebischer, T.; Stierhof, Y.D.; Fuchs, M.; Overath, P. J. Cell Sci., 1995, 108, 3715.

[232] Piani, A.; Ilg, T.; Elefanty, A.G.; Curtis, J.; Handman, E. Microbes Infect., 1999, 1, 589 .

[233] Pimenta, P.F.P.; De Souza, W. Exp. Parasitol., 1987, 63, 117

[234] Pimenta, P.F.P.; Dos Santos, M.A.V.; De Souza, W. J.Submicrosc. Cytol., 1987, 19, 387.

[235] Pimenta, P.F.; Saraiva, E.M.; Rowton, E.; Modi, G.B.; Garraway, L.A.; Beverley, S.M.; Turco, J.; Sacks, D.L. Proc. Natl. Acad. Sci. USA, 1994, 91, 9155 .

[236] Pingel, S.; Wang, Z.E.; Locksley, R.M. Infect. Immun., 1998, 66, 1795 .

[237] Plewes, K.A.; Barr, S.D.; Gedamu, L. Infect. Immun., 2003, 71, 5910.

[238] Privé, C.; Descoteaux, A. Eur. J. Immunol., 2000, 30, 2235.

[239] Puentes, S.M.; Sacks, D.L.; Da Silva, R.P.; Joiner, K.A. J. Exp. Med., 1988, 167, 887.

[240] Qiu, Z.H.; Gijón, M.A.; Carvalho, M.S.; Spencer, D.M.; Leslie, C.C. J. Biol. Chem., 1998, 273, 8203 .

[241] Qureshi, A.A.; Asahina, A.; Ohnuma, M.; Tajima, M.; Granstein, R.D.; Lerner, E.A. Am. J. Trop. Med. Hyg., 1996, 54, 665.

[242] Rainey, P.M.; Spithill, T.W.; McMahon-Pratt, D.; Pan, A.A. Mol. Biochem. Parasitol., 1991, 49, 111.

[243] Rasmusson, B.J.; Flanagan, T.D.; Turco, S.J.; Epand, R.M.; Petersen, N.O. Biochim. Biophys. Acta, 1998, 1404, 338.

[244] Rauch, C.A.; Pérez-Morga, D.; Cozzaelli, N.R.; Englund, P.T. EMBO J., 1993, 12, 403.

[245] Ray, M.; Gam, A.A.; Boykins, R.A.; Kenney, R.T. J. Infect. Dis., 2000, 181, 1121

[246] Reiner, N.E. J. Immunol., 1987, 138, 1919.

[247] Reiner, N.E.; Malemud, C.J. J. Immunol., 1985, 134, 556.

[248] Reiner, S.L.; Zheng, S.; Wang, Z.E.; Stowring, L.; Locksley, R.M. J. Exp. Med., 1994, 179, 447.

[249] Reis, I.A.; Martinez, M.; Yarlett, N.; Johnson, P.J.; Costae-Silva, F.C.; Vannier-Santos, M.A. Antimicrob. Agents Chemother., 1999, 43, 1919.

[250] Richards, P.S., Saba, T.M.; Del Vecchio, P.J.; Vincent, P.A.; Gray, V.C. Exp. Mol. Pathol., 1986, 45, 1 .

[251] Rittig, M.G.; Bogdan, C. Parasitol. Today, 2000, 16, 292

[252] Rizvi, F.S.; Ouassi, M.A.; Marty, B.; Santoro, F.; Capron, A. Eur. J. Immunol., 1988, 18, 473.

[253] Roberts, M.; Alexander, J.; Blackwell, J.M. J. Immungenet., 1990 17,89 .

[254] Robledo, S.; Wozencraft, A.; Valencia, A.Z.; Saravia, N. J. Immunol., 1994, 152, 1265 .
[255] Romão, P.R.; Fonseca, S.G.; Hothersall, J.S.; Noronha-Dutra, A.A.; Ferreira, S.H.; Cunha, F.Q. Parasitol., 1999, 118, 559.

[256] Rosenthal, E.; Marty, P. J. Postgrad. Med., 2003, 49, 61.

[257] Rosenthal, L.A.; Sutterwala, F.S.; Kehrli, M.E.; Mosser, D.M. Infect. Immun., 1996, 64, 2206.

[258] Russell, D.G. Eur. J. Biochem., 1987, 164, 213.

[259] Russell, D.G.; Wright, S.D. J. Exp. Med., 1988, 168, 279.

[260] Russell, D.G.; Xu, S.; Chakraborty, P. J. Cell Sci., 1992, 103, 1193

[261] Sacerdoti-Sierra, N.; Jaffe, C.L. J. Biol. Chem., 1997, 272, 30760.

[262] Sacks, D.L. Exp. Parasitol., 1989, 69, 100

[263] Sacks, D.L.; Perkins, P.V. Science, 1984, 223, 1417.

[264] Sacks, D.L.; Perkins, P.V. Am. J. Trop. Med. Hyg., 1985, 343, 456.

[265] Sacks, D.L.; Saraiva, E.M.; Rowton, E.; Turco, S.J.; Pimenta, P.F.P. Parasitol., 1994, 108, S55.

[266] Sacks, D.L.; Modi, G.; Rowton, E.; Spath, G.; Epstein, L.; Turco, S.J.; Beverley, S.M. Proc. Natl. Acad. Sci. USA, 2000, 97, 406.

[267] Santoro, G.F.; Valentim, C.; Lanfredi-Rangel, A.; C.; Yarlett, N.; Vannier-Santos, M.A. Mem. Inst. Oswaldo Cruz, 2000, 95, 67.

[268] Santos, C. X.; Bonini, M. G.; Augusto, O. Arch. Biochem. Biophys., 2000, 377, 146.

[269] Saraiva, E.M.B.; Vannier-Santos, M.A.; Silva-Filho, F.C.; De Souza, W. J. Cell Sci., 1989, 93, 481.

[270] Sawai, H.; Okasaki, T.; Takeda, Y.; Tashima, M.; Sawada, H.; Okuma, M.; Kishi, S.; Umehara, H.; Domae, N. J. Biol. Chem., 1997, 272, 2452

[271] Schaible, U.E.; Schlesinger, P.H.; Steinberg, T.H.; Mangel, W.F.; Kobayashi, T.; Russell, D.G. J. Cell Sci., 1999, 112, 681.

[272] Schlein, Y. Parasitol. Today, 1993, 9, 255

[273] Schlein, Y.; Jacobson, R.L.; Shlomai, J. Proc. R. Soc. Lond. B. Biol. Sci., 1991, 245, 121

[274] Scianimanico, S.; Desrosiers, M.; Dermine, J.F. Meresse, S.; Descoteaux, A.; Desjardins, M. Cell Microbiol., 1999, 1, 19.

[275] Seay, M.B.; Heard, P.L.; Chaudhuri, G. Infect. Immun., 1996, 64, 5129.

[276] Sem, G.; Ghosal, J.; Naskar, K.; Biswas, T. Ann. Trop. Med. Parasitol., 2000, 94, 43.

[277] Sengupta, S.; Tripathi, J.; Tandon, R.; Raje, M.; Roy, R.P.; Basu, S.K.; Mukhopadhyay, A. J. Biol. Chem., 1999, 274, 2758.

[278] Shankar, A.; Mitchen, T.K.; Hall, L.R.; Turco, S.J.; Titus, R.G. Mol. Biochem. Parasitol., 1993, 61, 207.

[279] Shapiro, T.A.; Englund, P.T. Ann. Rev. Microbiol., 1995, 49, 17.

[280] Silva-Filho, F.C.; Saraiva, E.M.B.; Vannier-Santos, M.A.; De Souza, W. Cell Biophys., 1990, 17, 137.

[281] Singh, I.; Chaudhury, V.P.; Wali, J.P. Transfusion, 1996, 36, 848.

[282] Singla, N.; Khuller, G.K.; Vinayak, V.K. FEMS Microbiol. Lett., 1992, 73, 221

[283] Smith, M.R.; Ramburg, E.A.; Kung, H.F.; Durum, S.K. J. Immunol., 1992, 149, 1304

[284] Soares, M.B.P.; Titus, R.G.; Shoemaker, C.B.; David, J.R.; Bozza, M. J. Immunol., 1998, 160, 1811.

[285] Song, M.M.; Shuai, K. Biol. Chem., 1998, 273, 35056.

[286] Soteriadou, K.P.; Remoundos, M.S.; Katsikas, M.C.; Tzinia, A.K.; Tsikaris, V.; Sakarellos, C.; Tzartos, S.J. J. Biol. Chem., 1992, 267, 13980.

[287] Souza, M.A.; Pereira, M.C.S.; Corte-Real, S. Mem. Inst. Oswaldo Cruz, 1997, 92, 761.

[288] Souza-Leão, S.; Lang, T.; Prina, E.; Hellio, R.; Antoine, J.C. J. Cell Sci., 1995, 108, 3219 .

[289] Späth, G.F.; Epstein, L.; Leader, B.; Singer, S.M.; Avila, H.A.; Turco, S.J.; Beverley, S.M. Proc. Natl. Acad. Sci. USA, 2000, 97, 9258.

[290] Späth, G.F.; Garraway, L.A.; Turco, S.T.; Beverley, S.M. Proc. Natl. Acad. Sci. USA, 2003, 100, 9536

[291] Speirs, K.; Caamano, J.; Goldschmidt, M.H.; Hunter, C.A.; Scott, P. J. Immunol, 2002, 168, 4406.

[292] St-Denis, A.; Caouras, V.; Gervais, F.; Descoteaux, A. J. Immunol., 1999, 163, 5503

[293] Stierhof, Y.D.; Bates, P.A.; Jacobson, R.L.; Rogers, M.E.; Schlein, Y.; Handman, E.; Ilg, T. Eur. J. Cell Biol., 1999, 78, 675.

[294] Stoiber, D.; Kovarik, P.; Cohney, S.; Johnston, J.; Steinlein, P.; Decker, T. J. Immunol., 1999, 163, 2640.

[295] Stoiber, D.; Stockinger, S.; Steinlein, P.; Kovarik, J.; Decker, T. J. Immunol, 2001, 166, 466.

[296] Sutterwala, F.S.; Mosser, D.M. J. Leuk. Biol., 1999, 65, 543.

[297] Sutterwala, F.S.; Rosenthal, L.A.; Mosser, D.M. J. Leuk. Biol., 1996, 59,883 . 
[298] Swindle, J.; Tait, A. In Molecular Biology of Parasitic Biology, Smith and Parsons, Eds.; IRL Press: Oxford, 1996; Vol. 13, pp. 634.

[299] Symmers, W.S.C. Lancet, 1960, 2, 127.

[300] Tachado, S.D.; Gerold, P.; Schwarz, R.; Novakovic, S.; McConville, M.; Schofield, L. Proc. Natl. Acad. Sci. USA, 1997, 94, 4022.

[301] Tachado, S.D.; Mazhari, R.; Schofield, L. Parasite Immunol., 1999, 21,609 .

[302] Talamas-Rohana, P.; Wright, S.D.; Lennartz, M.R.; Russell, D.G. J. Immunol., 1990, 144, 4817.

[303] Taylor, B.S.; Liu, S.; Villavicencio, R.T.; Ganster, R.W.; Geller, D.A. Hepatol., 1999, 29, 1199.

[304] Theodos, C.M.; Titus, R.G. Parasite Immunol., 1993, 15, 481

[305] Titus, R.G.; Ribeiro, J.M. Science, 1988, 239, 1306.

[306] Tripathi, A.; Gupta, C.M. Mol. Biochem. Parasitol., 2003, 128, 1.

[307] Tolson, D.L.; Turco, S.J.; Pearson, T.W. Infect. Immun., 1990, 58, 3500 .

[308] Tovar, J.; Cunninham, M.L.; Smith, A.C.; Croft, S.L.; Fairlamb, A.H. Proc. Natl. Acad. Sci. USA, 1998, 95, 5311.

[309] Turco, S. Exp. Parasitol., 1990, 70, 241

[310] Valenzuela, J.G.; Belkaid, Y.; Garfield, M.K.; Mendez, S.; Kamhawi, S.; Rowton, E.D.; Sacks, D.L.; Ribeiro, J.M. J. Exp. Med. 2001, 194, 331.

[311] van de Water III, L.; Schroeder, S.; Crenshaw III, E.B.; Hynes, R.O. J. Cell Biol., 1981, 90, 32

[312] Vannier-Santos. M.A.; Martiny, A.; De Souza, W. Curr. Pharmaceut. Des., 2002, 8, 297.

[313] Vannier-Santos, M.A.; Martiny, A.; Meyer-Fernandes, J.R.; De Souza, W. Eur. J. Cell Biol., 1995, 67, 112.

[314] Vannier-Santos, M.A.; Martiny, A.; Lins, U.; Urbina, J.A.; Borges, V.M.; De Souza, W. Microbiol., 1999, 145, 3213.

[315] Vannier-Santos, M.A.; Pimenta, P.F.P.; De Souza, W. J. Submicrosc. Cytol. Pathol., 1988, 20, 583.

This article is an update of the original article published in Current Pharmaceutical Design, Vol. 8, No. 4, December 2002, 297-318.
[316] Vannier-Santos, M.A.; Saraiva, E.M.B.; De Souza, W. Mem. Inst. Oswaldo Cruz, 1990, 86, 125.

[317] Vannier-Santos, M.A.; Saraiva, E.M.B.; De Souza, W. J. Histochem. Cytochem., 1991, 39, 793.

[318] Vannier-Santos, M.A.; Saraiva, E.M.B.; Martiny, A.; Neves, A.; De Souza, W. Eur. J. Cell Biol., 1992, 59, 389.

[319] Vannier-Santos, M.A.; Urbina, J.A.; Martiny, A.; Neves, A.; De Souza, W. J. Eukaryot. Microbiol., 1995, 42, 337.

[320] van Zandbergen, G.; Hermann, N.; Laufs, H.; Solbach, W.; Laskay, T. Infect. Immun., 2002, 70, 4177.

[321] Vodovotz, Y.; Bodgan, C.; Paik, J.; Xie, Q.W.; Nathan, C. J. Exp. Med., 1993, 178, 605.

[322] Waitumbi, J.; Warburg, A. Infect. Immun., 1998, 66, 1534.

[323] Walton, B.C. Intl. J. Dermatol., 1990, 28, 305.

[324] Webster, P.; Russell, D.G. Parasitol. Today, 1993, 9, 201.

[325] Whitfield, J.F.; MacManus, J.P.; Rixon, R.H.; Boyton, A.L; Youdale, T.; Swierenga, S.H.H. In Vitro, 1976, 12, 1.

[326] Wiese, M. EMBO J., 1998, 17, 2619.

[327] Wilson, E.; Olcott, M.C.; Bell, R.M.; Merrill, A.H.; Lambeth, J.D. J. Biol. Chem., 1986, 261, 12616.

[328] Wilson, M.E.; Pearson, R.D. Infect. Immun., 1988, 56, 363.

[329] Wozencraft, A.O.; Sayers, G.; Blackwell, J.M. J. Exp. Med., 1986, 164, 1332.

[330] Wright, S.D.; Licht, M.R.; Craigmyle, L.S.; Silverstein, S.C. J. Cell Biol., 1984, 99, 336.

[331] Wyler, D.J.; Sypek, J.P.; McDonald, J.A. Infect. Immun., 1985, 49, 305.

[332] Zhang, G.; Wu, H.; Ross, C.R.; Minton, J.E.; Blecha, F. Infect. Immun., 2000, 68, 1068.

[333] Zheng, L.; Zomerdijk, T.P.; Aanoudse, C.; van Furth, R.; Nibbering, P.H. J. Immunol., 1995, 155, 776.

[334] Zufferey, R.; Allen, S.; Barron, T.; Sullivan, D.R.; Denny, P.W.; Almeida, I.C.; Smith, D.F.; Turco, S.J.; Ferguson, M.A.J.; Beverley, S.M. J. Biol. Chem., 2003, (in press). 